Supporting Information

\title{
Smelling Sulfur: Copper and Silver Regulate the Response of Human Odorant Receptor OR2T11 to Low-Molecular-Weight Thiols
}

Shengju Li, ${ }^{\dagger}$ Lucky Ahmed, ${ }^{\star}$ Ruina Zhang, ${ }^{\dagger}$ Yi Pan, ${ }^{\dagger}$ Hiroaki Matsunami, ${ }^{\S}$ Jessica L. Burger,*,${ }^{\prime \prime}$ Eric Block, ${ }^{*}, \perp$ Victor S. Batista, ${ }^{*},+$ and Hanyi Zhuang, ${ }^{*},, \#$

${ }^{\dagger}$ Department of Pathophysiology, Key Laboratory of Cell Differentiation and Apoptosis of National Ministry of Education, Shanghai Jiaotong University School of Medicine, Shanghai 200025, China

${ }^{\ddagger}$ Department of Chemistry, Yale University, New Haven, Connecticut 06520, United States

${ }^{\S}$ Department of Molecular Genetics and Microbiology and Department of Neurobiology, Duke Institute for Brain Sciences, Duke University Medical Center, Durham, North Carolina 27710, United States

"Applied Chemicals and Materials Division, National Institute of Standards and Technology, Boulder, Colorado 80305, United States

${ }^{\perp}$ Department of Chemistry, University at Albany, State University of New York, Albany, New York 12222, United States

\#Institute of Health Sciences, Shanghai Jiaotong University School of Medicine/Shanghai Institutes for Biological Sciences of Chinese Academy of Sciences, Shanghai 200031, China 


\section{Table of Contents}

\begin{tabular}{|c|c|c|}
\hline \multicolumn{2}{|c|}{ Experimental Section } & \multirow{2}{*}{$\begin{array}{l}\text { S3 } \\
\text { S7 } \\
\end{array}$} \\
\hline Figure S1 & Screening for metal effect in known OR-ligand pairs & \\
\hline Figure S2 & OR2W1 and OR2C1 respond to selected monothiols & S10 \\
\hline Figure S3 & $\begin{array}{l}\text { OR2T11 responds to selected thiol compounds in the GloSensor }{ }^{\mathrm{TM}} \text { cAMP } \\
\text { assay }\end{array}$ & S11 \\
\hline Figure S4 & OR2T11 responds to selected monothiols and $\alpha$-mercaptothioethers & S13 \\
\hline Figure S5 & OR2T11 responds to $\alpha$-mercaptothioethers and sodium hydrosulfide & S14 \\
\hline Figure S6 & The copper effect of OR2T11 and MOR244-3 with $\mathrm{CuCl}$ & S15 \\
\hline Figure S7 & $\begin{array}{l}\text { Both OR2T11 and MOR244-3 respond to thietane in the GloSensor }{ }^{\mathrm{TM}} \\
\text { cAMP assay }\end{array}$ & S16 \\
\hline Figure S8 & Screening for MOR244-2 ligands & S17 \\
\hline Figure S9 & Binding sites of OR2T11 & S18 \\
\hline Figure S10 & OR2T11 control mutants & S19 \\
\hline Figure S11 & $\begin{array}{l}\text { QM/MM optimized models of (A) EtSH, (B) } n \text {-PrSH, (C) } i \text {-PrSH, (D) } \\
\text { 2-propenethiol, (E) (methylthio)methanethiol, and (F) methanethiol }\end{array}$ & S20 \\
\hline Figure S12 & $\begin{array}{l}\text { QM/MM optimized models of (A) } i \text {-PrSH and (B) } t \text {-BuSH bound to copper } \\
\text { ion in Site } 2 \text { of OR2T11 }\end{array}$ & S21 \\
\hline Figure S13 & $\begin{array}{l}\text { Multiple sequence alignment of the human M2 muscarinic receptor, human } \\
\text { olfactory receptor OR2T11, mouse olfactory receptor MOR244-3 and } \\
\text { mouse olfactory receptor MOR244-2 }\end{array}$ & S22 \\
\hline Figure S14 & TMHMM posterior probabilities for OR2T11 & S23 \\
\hline Figure S15 & $\begin{array}{l}\text { Multi sequence Stamp alignment of the seven TM regions of the homology } \\
\text { model of OR2T11, MOR244-3, MOR244-2 with the human M2 muscarinic } \\
\text { receptor }\end{array}$ & S24 \\
\hline Figure S16 & $\begin{array}{l}\text { Predicted metal binding sites in OR2T11, including site } 1 \text { (M115, C238 and } \\
\text { H241) and site } 2 \text { (M56, M133, R135 and C138) }\end{array}$ & S25 \\
\hline Figure S17 & $\begin{array}{l}\text { The response of MOR244-2 mutants }(\mathrm{C} 112 \mathrm{~A}, \mathrm{C} 112 \mathrm{M} \text { and } \mathrm{C} 112 \mathrm{~V}) \text { to } \\
\text { copper }\end{array}$ & S26 \\
\hline Table S1 & A list of sulfur-containing compounds used on OR2T11 and MOR244-3 & S27 \\
\hline Table S2 & $\begin{array}{l}\text { EC }_{50} \text { deduced from the dosage response curves for OR2T11 and } \\
\text { MOR244-3 in the luciferase assay }\end{array}$ & S29 \\
\hline Table S3 & $\begin{array}{l}\text { A list of compounds in the mixture panel screened on MOR244-2 in Figure } \\
\text { S8 }\end{array}$ & S30 \\
\hline Table S4 & $\begin{array}{l}\text { QM/MM calculated binding energy for different thiols and hydrogen } \\
\text { sulfide }\end{array}$ & S35 \\
\hline Table S5 & A list of primers used for OR2T11 and MOR244-2 mutagenesis & S36 \\
\hline References & & S38 \\
\hline
\end{tabular}




\section{Experimental Section}

\section{Chemicals}

The sources of metal ions used are as follows: $\mathrm{CuCl}_{2}, \mathrm{CuCl}, \mathrm{NiCl}_{2}, \mathrm{ZnSO}_{4}$, and $\mathrm{AgAc}$ (Sigma-Aldrich), $\mathrm{CoCl}_{2}$ (Sinopharm), $\mathrm{MgCl}_{2}$ (Takara), and $\mathrm{FeCl}_{3}, \mathrm{AgNO}_{3}, \mathrm{MnCl}_{2}, \mathrm{AuCl}_{3}$, and $\mathrm{PtCl}_{2}$ (Aladdin Reagent). Colloidal silver and tetraethylenepentamine were purchased from Sigma-Aldrich. The sources of odorants used are listed in Table S1. All odorants were dissolved in DMSO or ethanol and diluted further into working concentrations before experiments.

\section{Cloning and Mutagenesis}

Our human OR library used for screenings includes 330 unique ORs that represent more than $80 \%$ of the total human OR genes. The ORs, along with an N-terminal rhodopsin tag, were cloned into the pCI mammalian expression vector between the NheI and NotI restriction enzyme sites. Using the wild type OR2T11 and MOR244-2 constructs as templates, site-directed mutagenesis of these receptors was carried out using overlap-extension PCR. The primers used for mutagenesis are listed in Table S5. The identities of all OR and mutant constructs were confirmed by sequencing.

\section{Luciferase and GloSensor ${ }^{\mathrm{TM}}$ cAMP Assays}

HEK293T-derived Hana3A cell line was grown in Minimum Essential Medium (Hyclone) containing $10 \%$ fetal bovine serum at $37{ }^{\circ} \mathrm{C}$ with $5 \% \mathrm{CO}_{2}$. For the luciferase assay, after 18 to 24 $\mathrm{h}, \mathrm{OR}$ or mutant receptor, the accessory factor, mRTP1S, and constructs for firefly luciferase and Renilla luciferase expression were transfected into cells for luciferase assay. For the GloSensor ${ }^{\mathrm{TM}}$ cAMP assay, OR, mRTP1S, and a GloSensor ${ }^{\mathrm{TM}}$ plasmid were transfected into cells. Lipofectamine 2000 (Invitrogen) was used for transfection. Twenty-four hours after transfection, the cells were stimulated with odorants and/or various metals ions dissolved in CD293 (Invitrogen) for the luciferase assay or Hank's Balanced Salt Solution for the GloSensor ${ }^{\mathrm{TM}}$ cAMP assay.

\section{Details on the Homology Model Approach}

We built the homology model of OR2T11 (NCBI Reference Sequence: NP_001001964.1) and MOR244-2 (GenBank: AAL60957.1) using the X-ray structure of the human M2 muscarinic receptor as a template. The comparative protein modeling with available X-ray structures indicates a high sequence identity between the OR2T11 and M2 receptor transmembrane (TM) regions (with an expected E value of about $1.3 * 10^{-37}$ for the homology model based on the M2 receptor, which is very satisfactory since a structure is not suitable for homology modeling when the E-value is higher than 1). Analogously, we found a comparably high sequence identity for MOR244-2. The homology model of MOR244-3 is also been based on the X-ray structure of the human M2 muscarinic receptor. ${ }^{1}$ Figure S13 shows the sequence alignment of the human M2 muscarinic receptor, ${ }^{2}$ mouse olfactory receptor MOR244-3, ${ }^{1}$ mouse olfactory receptor MOR244-2, and human olfactory receptor OR2T11 as obtained by using the Multiple Sequence Viewer implemented in Maestro. ${ }^{3}$ The TM domains were obtained by using the transmembrane hidden Markov Model (TMHMM) analysis, as applied to model MOR244-3, ${ }^{1}$ using the 
TMHMM server (http://www.cbs.dtu.dk/services/TMHMM/) based on Bayesian analysis of a pool of transmembrane proteins with resolved structures. As shown in Figure S14, OR2T11 residues with a posterior TM probability greater than 0.1 were assigned to the transmembrane domain. Figure S15 shows the superposition of structures corresponding to the multi sequence alignment of TM regions of OR2T11 (blue, Figure S15A) with the human M2 muscarinic receptor (reddish pink) and the mouse olfactory receptor MOR244-3 (3UON.pdb). Figure S15B shows the aligned structure of OR2T11 (blue) superimposed to the structure of the mouse olfactory receptor MOR244-3 (red). Similarly, Figures S15C and S15D) show the superposition of homology models for the MOR244-2 (green), the human M2 muscarinic receptor (reddish pink) and MOR244-3 (red).

\section{Details on the Preparation of the Protein and QM/MM Setup}

The initial coordinates of the OR2T11 and MOR244-2 structures were obtained from the homology models of OR2T11 and MOR244-2, as described above. For OR2T11, the residue C119 is mutated to R119 to be consistent with experimental work. Then the proteins were processed to assign the bond orders, add hydrogen atoms and to create disulfide bonds, using the preparation wizard in Maestro. The protonation states of all titratable residues at physiological $\mathrm{pH}=7$ are assigned according to PROPKA calculations, ${ }^{4}$ as implemented in the Schrodinger's Maestro 10.2.010 software package, ${ }^{3}$ and visualized for inspection. In the final stage of protein preparation, we relaxed the protein structure using the OPLS2005 force field as implemented in Maestro to avoid internal residues clashes. ${ }^{5}$ The organosulfur ligands were preoptimized by energy minimization at the DFT-M06L/6-31G(d) level of theory. ${ }^{6-8}$ The optimized thiols were considered as the initial geometry and inserted into the binding site of the receptor for DFT-QM/MM calculations, including explicit van der Waals, steric and electrostatic interactions with the protein environment. To minimize structural changes, the full structure was relaxed via a three-step optimization procedure. In the first stage, the structure was fully optimized at the pure AMBER96 force field level ${ }^{9}$ followed by reoptimization at the two-layer ONIOM scheme with electronic-embedding (EE) ${ }^{10}$ as implemented in Gaussian09. ${ }^{11}$ The QM layer included the metal ion (e.g., $\mathrm{Cu}(\mathrm{I}), \mathrm{Ag}(\mathrm{I})$ ) and surrounding amino acid residues as well as the thiol ligands (if any), treated at the M06-L $\mathrm{L}^{6,7}$ level of theory, using the Stuttgart [8s7p6d2f | 6s5p3d2f] ECP10MWB contracted pseudopotential basis set ${ }^{12}$ on $\mathrm{Cu}$, SDD basis set ${ }^{12}$ on Ag and the 6-31G(d) basis $\operatorname{set}^{8}$ on all other atoms. The MM layer included the rest of the protein, as described by the AMBER96 molecular mechanics force field. ${ }^{9}$ The interface between QM and MM layers was treated using the standard hydrogen-link atom scheme, ${ }^{13}$ as previously implemented for studies of a variety of other visual and non-visual GPCRs. ${ }^{1,14}$

\section{Details on the Determination of the Metal Binding Site}

To determine the possible metal binding site(s) in the protein, we looked for clusters of amino acid residues, such as His, Cys, Met and Arg known to coordinate metals, such as copper in other proteins. ${ }^{115-17} \mathrm{We}$ found two possible binding sites in OR2T11, including site 1 with the proximal Met115, C238 and $\mathrm{H} 241$ residues. Arg119 is also close to site 1. A second binding site includes M56, M133, Arg135 and C138 (Figure S16). We also explored several other possible binding sites where clusters of His/Cys/Met amino-acid residues are available and could coordinate to a metal center, including C186/H263, C176/H173/C94, and H223/C124. However, 
we found that the amino acid residues were not sufficiently close as to coordinate to a common metal ion. For example, C186 and H263 are about 7.0 $\AA$ apart from each other. Similarly, the $\mathrm{H} 223 / \mathrm{C} 124$ pair is also separated by about $10.0 \AA$. The C176/H173/C94 cluster could in principle be a binding site but the $\mathrm{C} 176-\mathrm{C} 94$ pair is compromised in a disulfide bond essential for protein structure and stability. Such a disulfide bond links the EII loop and the TM3 regions and is highly conserved in other ORs, such as MOR244- $3^{1}$ and MOR256-17. ${ }^{18}$ Therefore, site 1 (Met115, C238 and H241) and site 2 (M56, M133, Arg135 and C138) seem to be the possible metal binding sites in OR2T11. The mutagenesis analysis is also consistent with this binding site prediction.

The sequence alignment of MOR244-3 and MOR244-2 was particularly useful to investigate possible metal binding sites in MOR244-2. We found that $\mathrm{Cu}(\mathrm{I})$ binds to M104 and H108. C112 is close to this binding site but does not seem to be crucial for copper binding (Figure S17), as shown by the analysis of the mutants of $\mathrm{C} 112 \mathrm{~A}$ and $\mathrm{C} 112 \mathrm{M}$. Other potential metal binding sites included pairs of His/Cys amino acid residues, including C243/H246, C75/H76 and C100/C182 that are close enough (within $4.0 \AA$ of each other) to coordinate to a common metal ion. However, the $\mathrm{C} 243 / \mathrm{H} 246$ pair was found improbable to be the active site since it is conserved in MOR244-2, as found in MOR244-3 and MOR256- 17, and MOR256-17 is insensitive to $\mathrm{Cu}$. The sequence alignment also shows that the C75/H76 pair in MOR244-2 and the C72/H73 pair in MOR244-3 are aligned. In MOR244-3, the C72/H73 pair was ruled out because activity was unchanged by the mutations $\mathrm{C} 72 \mathrm{~V}, \mathrm{H} 73 \mathrm{Y}$, and H73F. ${ }^{18}$ Therefore, we conclude the $\mathrm{C} 75 / \mathrm{H} 76$ pair is not the metal binding site. In addition, as mentioned before, we ruled out the C100/C182 pair since it is involved in forming a disulfide bond that is crucial for the protein structure.

\section{Details on the Calculation of Binding Affinities}

We have calculated the binding energies to compare the relative binding affinity of thiol ligands to the receptor. The protein complexes (containing both copper and the ligand) were optimized with DFT-QM/MM platform to get the total energy ( $\left.\mathrm{E}_{\text {Total energy of the complex }}\right)$ of the complex. As described in the QM/MM setup section, the QM layer included the $\mathrm{Cu}$ ion, responsible amino acid residues and thiol ligands (if any) treated at M06-L level of theory, using the Stuttgart [8s7p6d2f |6s5p3d2f] ECP10MWB contracted pseudopotential basis set on $\mathrm{Cu}$, and the 6-31G(d) basis set on all other atoms. The MM layer included the rest of the protein as described by the AMBER96 molecular mechanics force field. The QM/MM optimization was also carried out for the protein containing only copper (but not the ligand) to compute the energy ( $E_{\text {Receptor }}$ ) of the receptor. We found the $E_{\text {Receptor value for the receptor is }-2042.296026 \text { a.u., which }}$ is constant for all binding energy calculations. The optimized structure of the ligands obtained in the QM/MM calculation was used to compute the single point energy ( $E_{\text {Odorant }}$ ) of the odorants/ligands, using DFT calculations on free ligands (Table S4). The relative binding energy was calculated, according to the following equation:

$$
\text { Binding Energy }=\mathrm{E}_{\text {Total energy of the complex }}-\left[\mathrm{E}_{\text {Receptor }}+\mathrm{E}_{\text {Odorant }}\right]
$$

For example, the binding energy of $t$-BuSH to the binding site is calculated, as follows: Binding Energy ( $t$-BuSH) 


$$
\begin{aligned}
& =-2598.36350582478-[(-2042.296026)+(-556.009804)] \text { A.U. } \\
= & -2598.36350582478+2598.30583 \text { A.U. } \\
= & -36.2 \mathrm{kcal} / \mathrm{mol}
\end{aligned}
$$

\section{Saturation-Transfer Difference NMR spectroscopy}

Transfected and non-transfected Hana3A cells were grown to confluency in T-75 flasks (approximately $10^{7}$ cells) and harvested by trypsinization and centrifugation at $200 \mathrm{~g}$ for $5 \mathrm{~min}$. The cell pellet was resuspended in $400 \mu \mathrm{L}$ HBSS. All preparations were done at room temperature. The suspension was then added to NMR tubes containing $100 \mu \mathrm{L} \mathrm{D}_{2} \mathrm{O}$ and odorant, for a final concentration of approximately $4 \mathrm{mmol} / \mathrm{L}$ odorant (actual concentrations were determined by the NMR ERETIC method) ${ }^{19}$. This preparation provided a cell concentration of approximately $2 \times 10^{7}$ cells per mL. Typical of GPCR-expressing cell lines is a receptor density of about $10^{6}$ per cell. For a transfection efficiency of $40 \%$, the receptor concentration is $8 \times 10^{12}$ receptors per $\mathrm{mL}(\sim 13 \mathrm{nmol} / \mathrm{L})$. In order to explore the metal response on odorant binding, 400 $\mu \mathrm{mol} / \mathrm{L} \mathrm{CuCl}{ }_{2}$ or $\mathrm{AgNO}_{3}$ was added to the solutions as indicated.

STD NMR spectra were obtained at $30{ }^{\circ} \mathrm{C}$ unless otherwise noted, with a sweep width of 16 ppm, and acquisition time of $3 \mathrm{~s}$ on a $600 \mathrm{MHz}$ spectrometer equipped with a $5 \mathrm{~mm}$ inverse double-resonance cryoprobe. Selective protein saturation was achieved by a set of Gaussian pulses of 50 ms length with $9.5 \mathrm{~W}$ power level. Forty selective pulses were applied, leading to a saturation time of $2 \mathrm{~s}$. On-resonance irradiation of the protein was performed at $-1.0 \mathrm{ppm}$, and the off-resonance irradiation was set at $-20 \mathrm{ppm}$, where neither protein nor ligand signals were present. The number of scans was 512, preceded by 8 dummy scans. Spectra were subtracted internally by phase cycling after every scan using different memory buffers for on- and offresonance data.

Four sources of uncertainty were considered for the peak integrals in our STD experiments: slight spectral deviations between the on-resonance and off-resonance spectrum that result in slight imperfections in subtraction; repeatability in the concentration of odorant receptor due to variations in transfection rate and cell density; baseline drift; and peak overlap. The STD effect may be evaluated by calculating the amplification factor $\left(A_{\mathrm{STD}}\right)$. The $A_{\mathrm{STD}}$ is obtained by multiplying the relative STD effect of a given signal (the intensity of the signal in the STD spectrum divided by the intensity of the signal in the reference spectrum $\left.\left(I_{\mathrm{STD}} / I_{0}\right)\right)$ with the molar ratio of ligand in excess relative to the protein ([odorant]/[OR]).

$$
A_{\text {STD }}=\frac{I_{\text {STD }}}{I_{0}} \times \frac{\text { [odorant }]}{[\text { OR }]}
$$

In addition to the uncertainty of the peak integrals, our calculation of the amplification factor used the ERETIC calculated concentration for the odorant and it should be noted that the ERETIC reference spectrum and the STD reference spectrum had different resolutions, which will lead to an increase in uncertainty. 

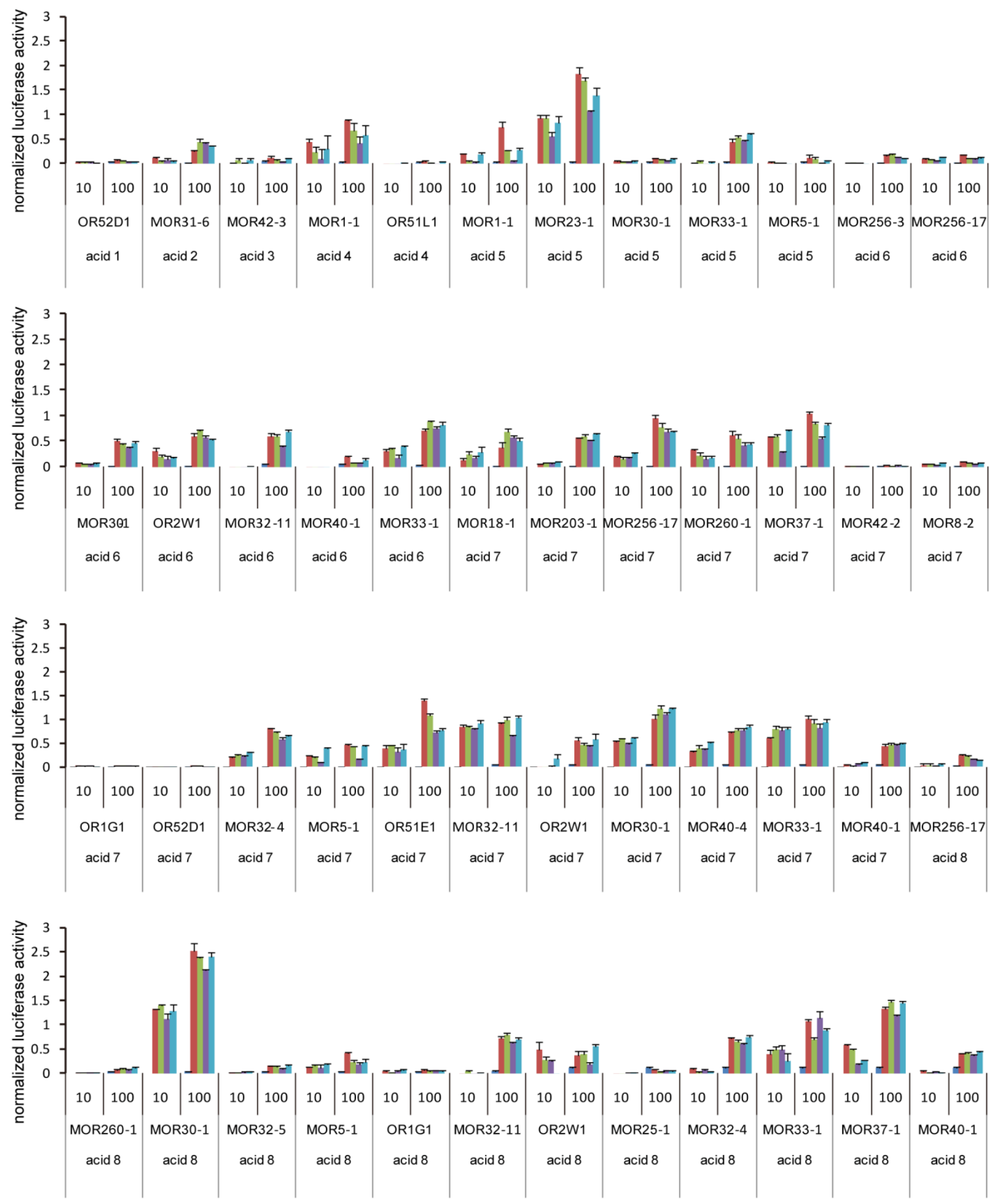


\section{A cont'd}
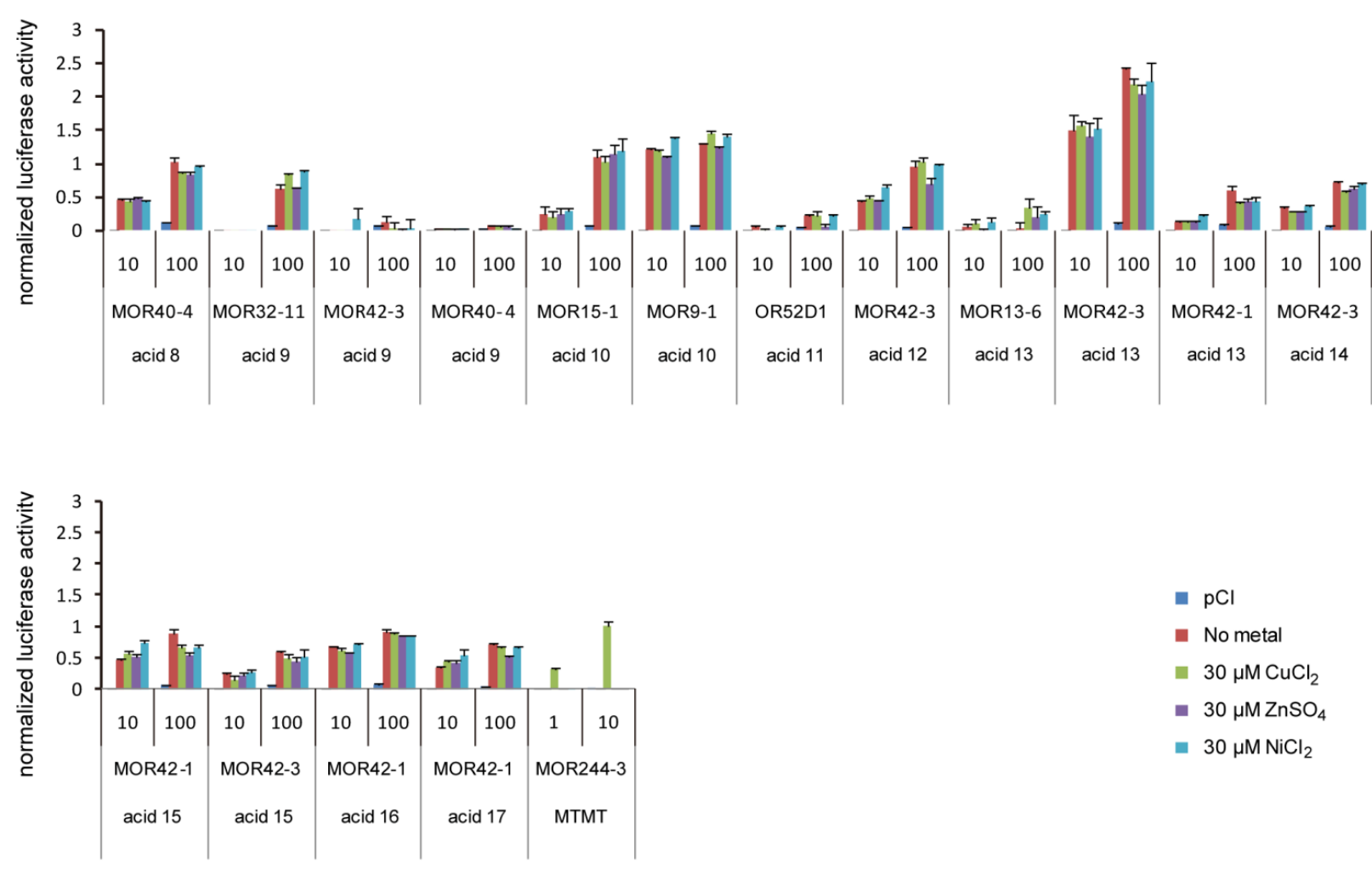

B

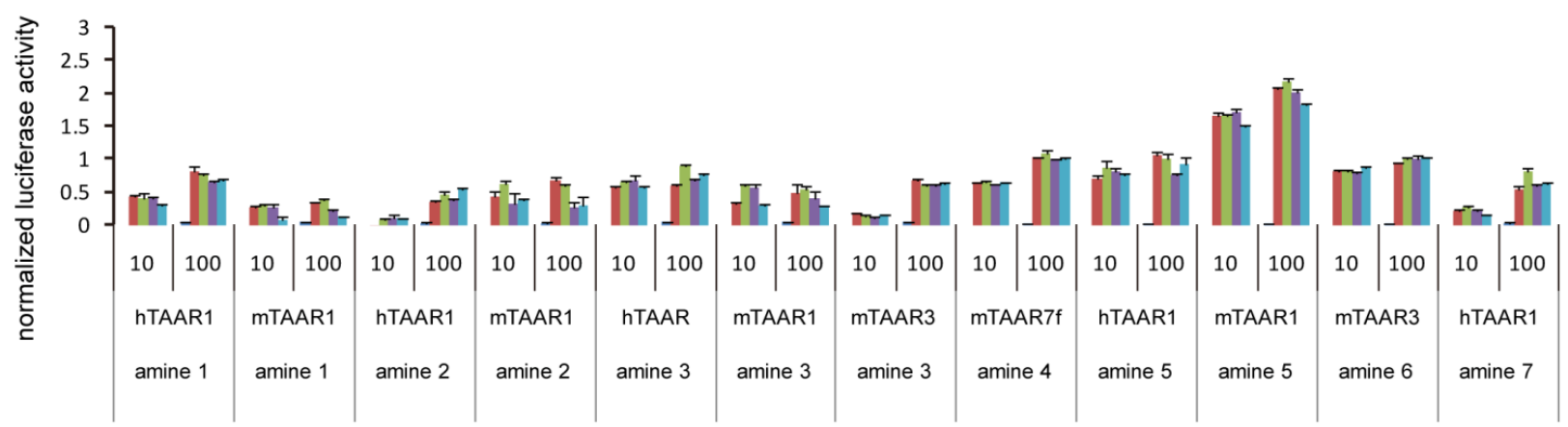

Figure S1. Screening for metal effect in known OR-ligand pairs. The responses to (A) carboxylic acids and (B) amines by different ORs with or without $30 \mu \mathrm{M} \mathrm{CuCl}_{2}, \mathrm{ZnSO}_{4}$, or $\mathrm{NiCl}_{2}$. All odorants were used at $10 \mu \mathrm{M}$ and $100 \mu \mathrm{M}$, except for the positive control ligand MTMT, which was used at $1 \mu \mathrm{M}$ and $10 \mu \mathrm{M}$. All responses are normalized to MOR244-3's response to MTMT at $10 \mu \mathrm{M}(N=3)$. The empty vector pCI was transfected to control for background responses to each odorant. Acid 1, butyric acid. Acid 2, isobutyric acid. Acid 3, bromobutanoic acid. Acid 4, hexanoic acid. Acid 5, heptanoic acid. Acid 6, octanoic acid. Acid 7, nonanoic acid. Acid 8, decanoic acid. Acid 9, undecanoic acid. Acid 10, vanillic acid. Acid 11, trans-cinnamic acid. Acid 12, octanedioic acid. Acid 13, nonanedioic acid. Acid 14, 5-oxononanedioic acid. Acid 15, decanedioic acid. Acid 16, undecanedioic acid. Acid 17, 
dodecanedioic acid. Amine 1, butylamine. Amine 2, isobutylamine. Amine 3, 3-(methylthio)-propylamine. Amine 4, $N$-methylpiperidine. Amine 5, hexylamine. Amine 6, cyclohexylamine. Amine 7, benzylamine. 
A
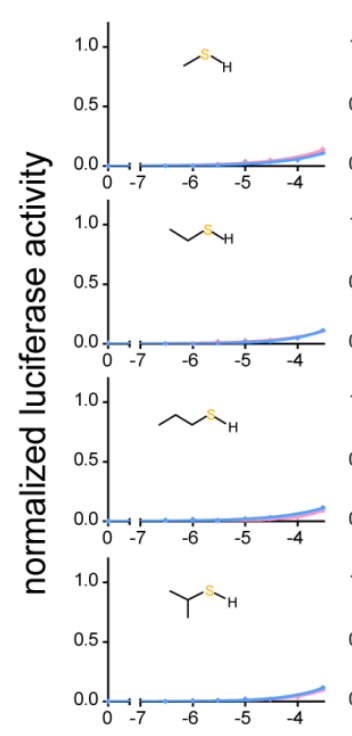

OR2W1
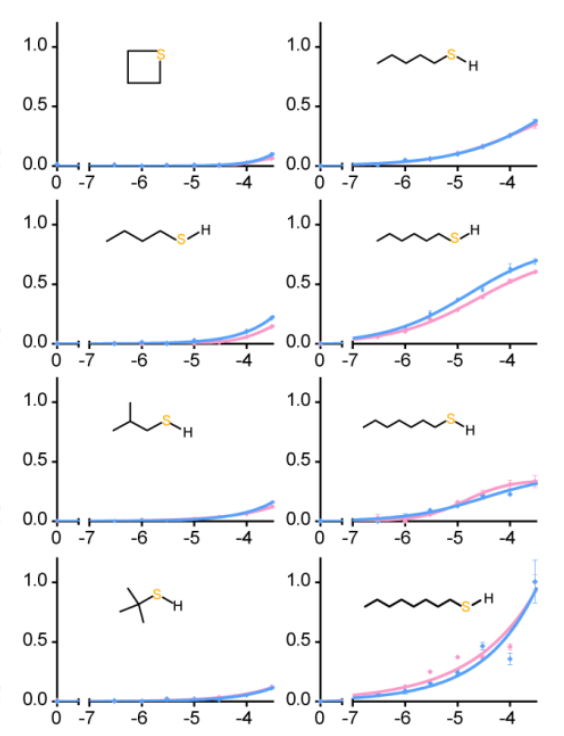

$\log [$ odorant] (M) $\log [$ odorant] $(M) \log [$ odorant] $(M)$
B OR2C1

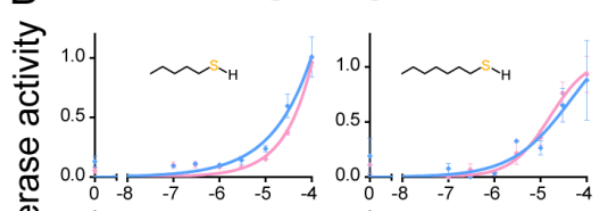

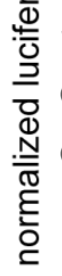

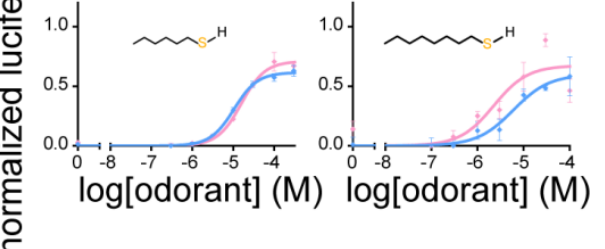

- no Cu added

- $30 \mu \mathrm{M}$ Cu added

Figure S2. OR2W1 and OR2C1 respond to selected monothiols. Dose-response curves of (A) OR2W1 and (B) OR2C1 to various monothiols in the luciferase assay. The $y$-axis indicates normalized response $\pm \operatorname{SEM}(N=3)$. All responses are normalized to the highest response of each receptor $(N=3)$. 
A
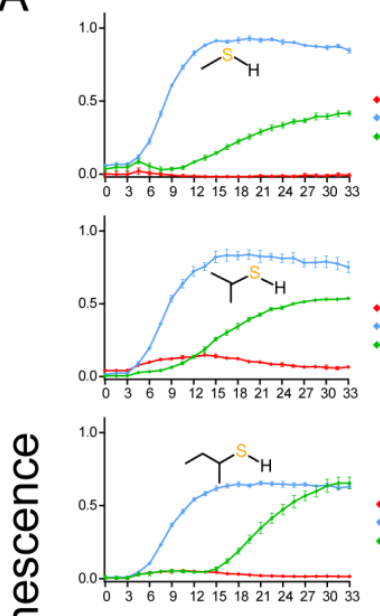

ह气

סָ
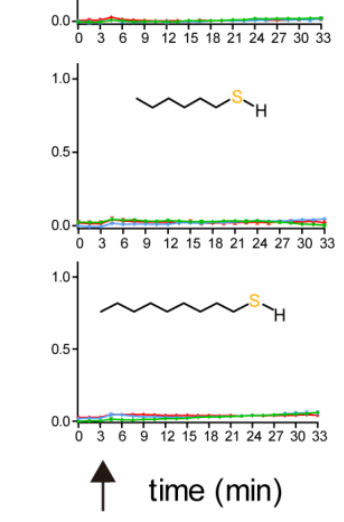

B

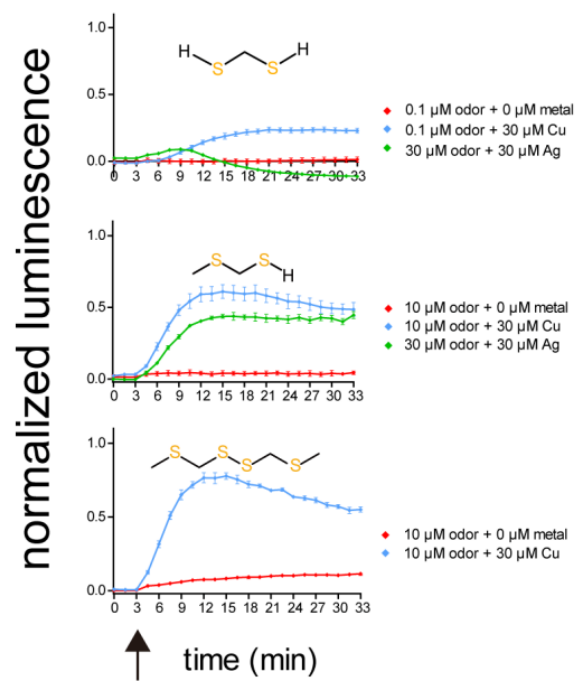
$300 \mu \mathrm{M}$ odor $+0 \mu \mathrm{M}$ metal
$300 \mu \mathrm{M}$ odor $+30 \mu \mathrm{M} \mathrm{Cu}$
$300 \mu \mathrm{M}$ odor $+30 \mu \mathrm{M} \mathrm{Ag}$ $300 \mu \mathrm{M}$ odor $+30 \mu \mathrm{M} \mathrm{Ag}$

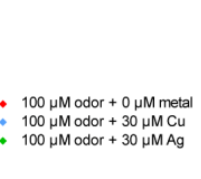

$-100 \mu \mathrm{M}$ odor $+0 \mu \mathrm{M}$ metal
$-100 \mu \mathrm{M}$ odor $+30 \mu \mathrm{M} \mathrm{Cu}$ $100 \mu \mathrm{M}$ odor $+30 \mu \mathrm{M} \mathrm{Cu}$
$100 \mu \mathrm{M}$ odor $+30 \mu \mathrm{M} \mathrm{Ag}$

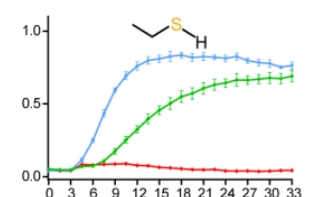

- $100 \mu \mathrm{M}$ odor $+0 \mu \mathrm{M}$ metal $100 \mu \mathrm{M}$ odor $+30 \mu \mathrm{M} \mathrm{Ag}$
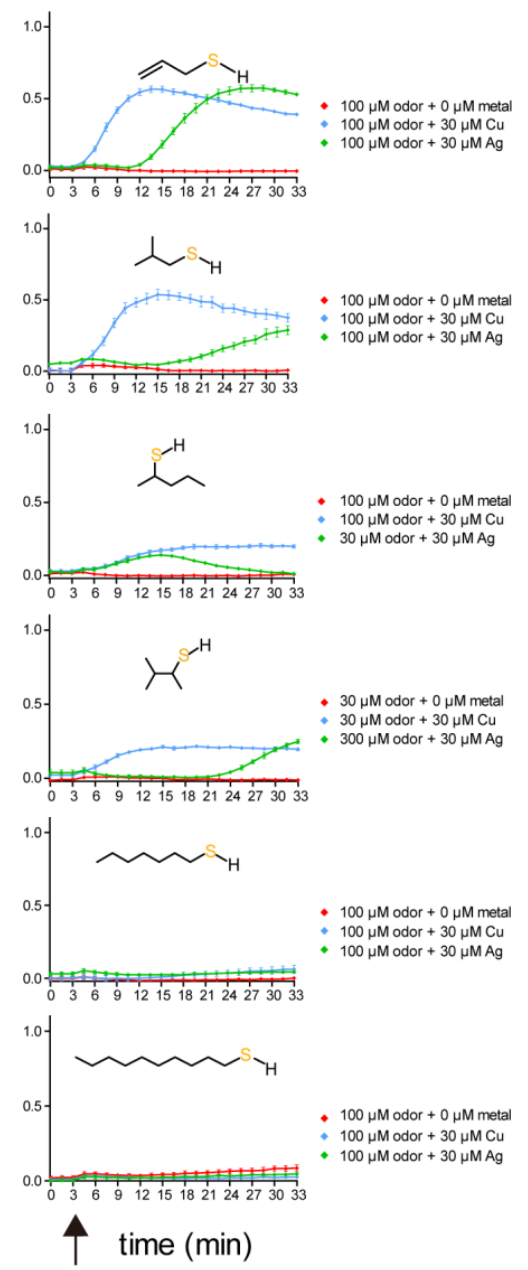

- $100 \mu \mathrm{M}$ odor $+0 \mu \mathrm{M}$ metal $100 \mu \mathrm{M}$ odor $+30 \mu \mathrm{M} \mathrm{Cu}$
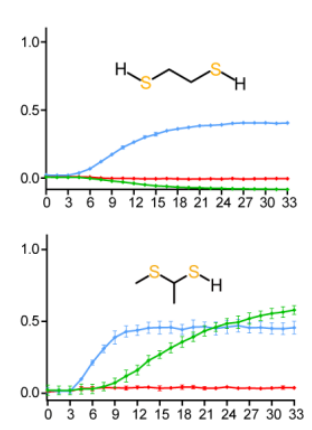

- $0.03 \mu \mathrm{M}$ odor $+0 \mu \mathrm{M}$ metal $0.03 \mu \mathrm{M}$ odor $+30 \mu \mathrm{M} \mathrm{Cu}$
$-0.03 \mu \mathrm{M}$ odor $+30 \mu \mathrm{M} \mathrm{Ag}$ $0.03 \mu \mathrm{M}$ odor $+30 \mu \mathrm{M} \mathrm{Ag}$

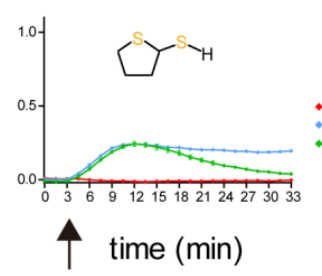

S11
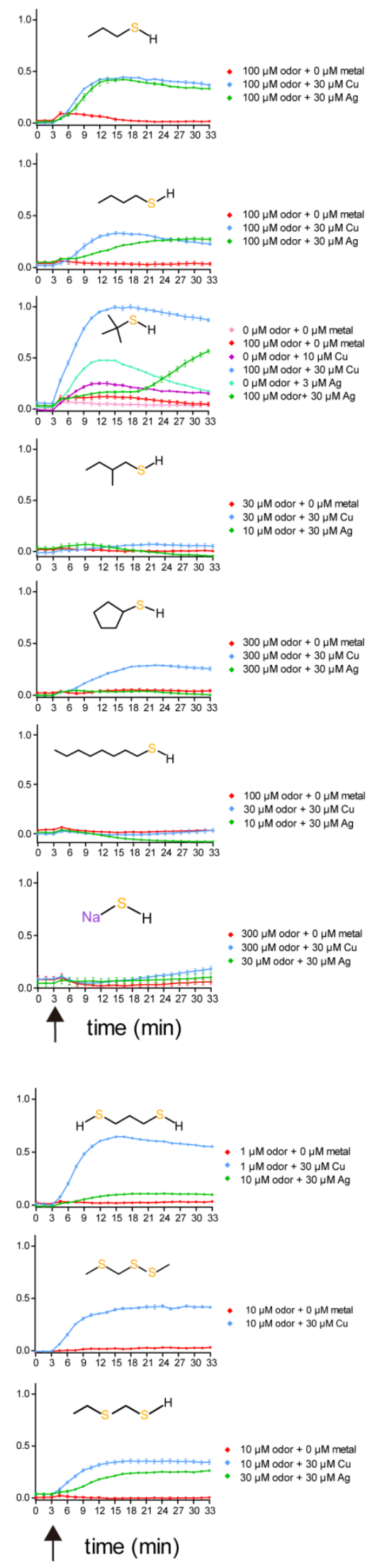
Figure S3. OR2T11 responds to selected thiol compounds in the GloSensor ${ }^{\mathrm{TM}}$ cAMP assay. Real-time measurement of OR2T11 activation in response to (A) monothiols and sodium hydrosulfide (at $\mathrm{pH}$ 6.14), and (B) dithiols and $\alpha$-mercaptothioethers as detected within 30 minutes of odorant addition. Metals used in the assay were $\mathrm{CuCl}_{2}$ and $\mathrm{AgNO}_{3}$, except for methanethiol and sodium hydrosulfide, where colloidal silver was used. The arrow along the $x$-axis indicates the time point of odorant addition. $y$-axis indicates normalized luminescence $\pm \operatorname{SEM}(N=3)$. All responses are normalized to the highest response of OR2T11 to TBM. 


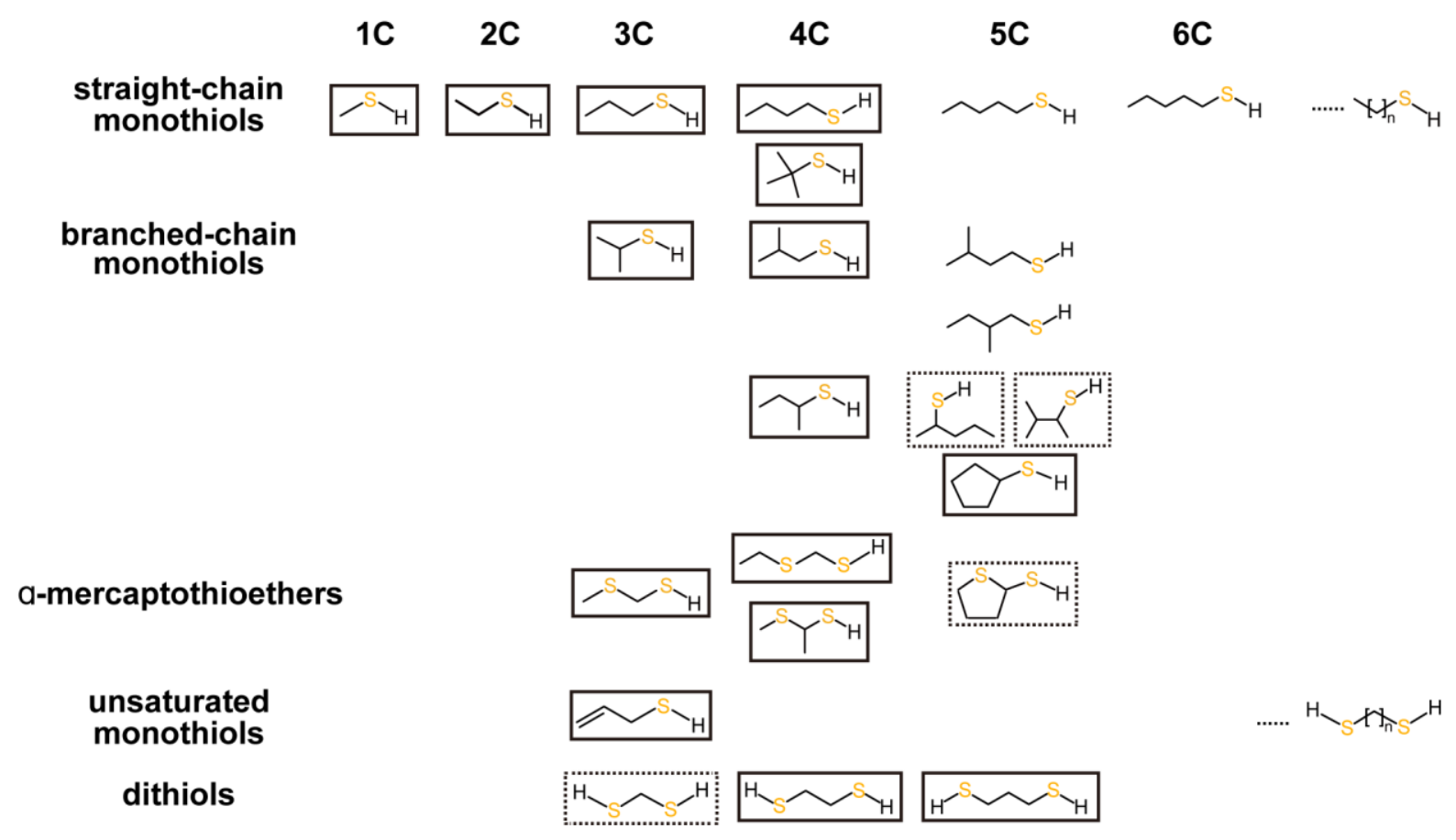

Figure S4. OR2T11 responds to selected monothiols and $\alpha$-mercaptothioethers. A schematic diagram of all relevant sulfur-containing compounds screened on OR2T11. Odors boxed with solid lines showed prominent responses in the presence of $30 \mu \mathrm{M} \mathrm{Cu}^{2+}$ and odors boxed with dashed lines showed less prominent responses, as defined by a more than $70 \%$ reduction in efficacy compared with TBM in the GloSensor TM cAMP assay in Figure S3. "1C" through "6C" refer to the number of the carbon atoms in the original straight-chain monothiol compounds. Straight-chain monothiols with $10>\mathrm{C}>5$ were tested and deemed inactive. 

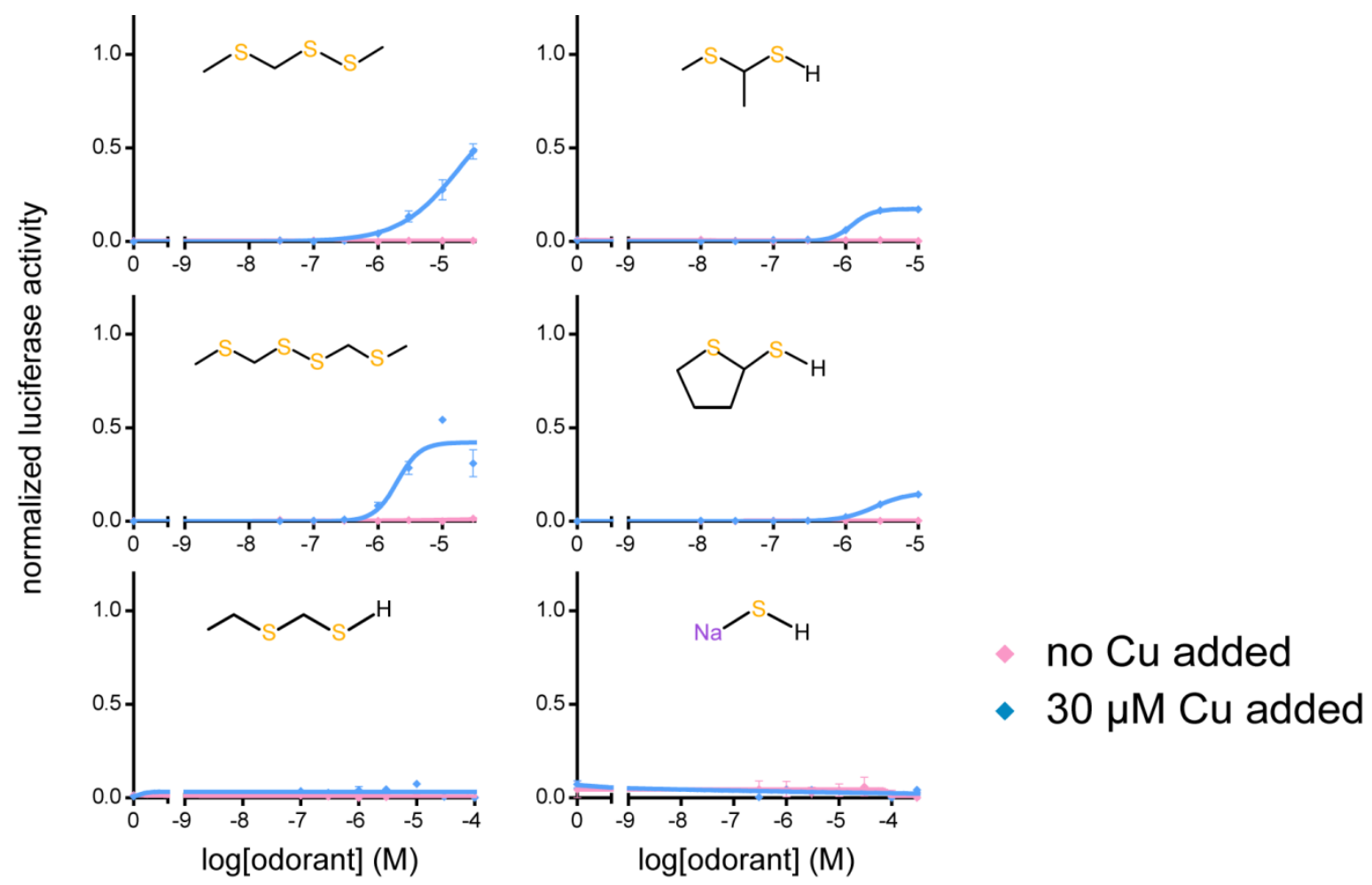

Figure S5. OR2T11 responds to $\alpha$-mercaptothioethers and sodium hydrosulfide. Dose-response curves of OR2T11 to 2,3,5-trithiahexane, 1-(methylthio)ethanethiol, bis(methylthiomethyl) disulfide, thiolane-2-thiol, (ethylthio)methanethiol, and sodium hydrosulfide (at $\mathrm{pH}$ 6.2). The $y$-axis indicates normalized response $\pm \operatorname{SEM}(N=3)$. All responses are normalized to the highest response to TBM. 

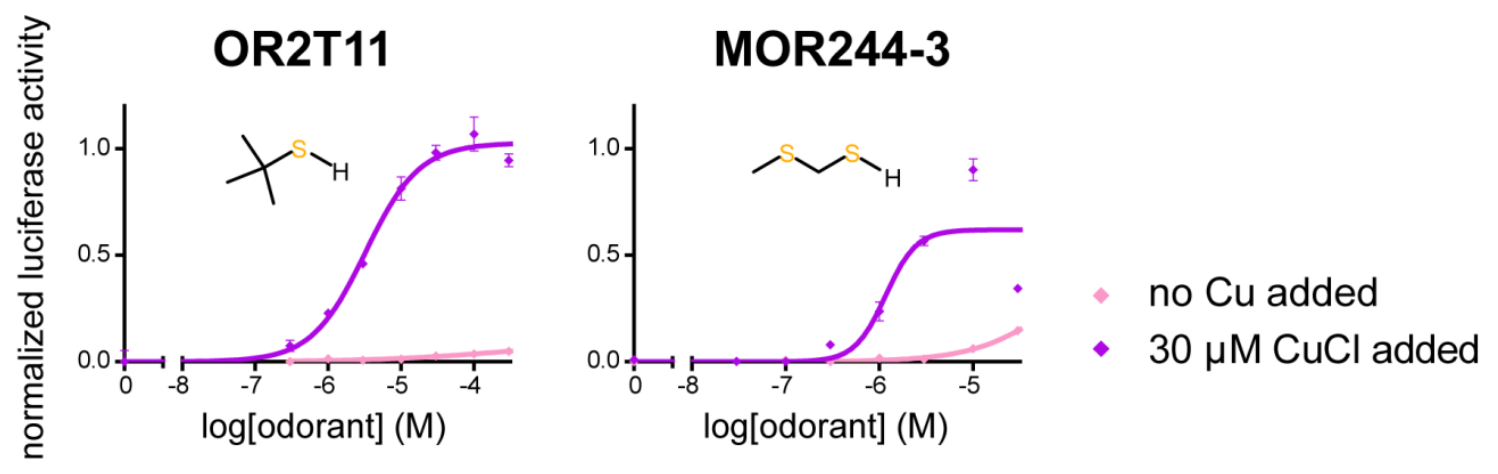

Figure S6. The copper effect of OR2T11 and MOR244-3 with $\mathrm{CuCl}$. Dose-response curves of OR2T11 to TBM and MOR244-3 to MTMT. The $y$-axis indicates normalized response \pm SEM $(N$ $=3$ ). Both responses are normalized to the highest response of the same receptor-ligand pair with $30 \mu \mathrm{M} \mathrm{CuCl}_{2}$ added. 

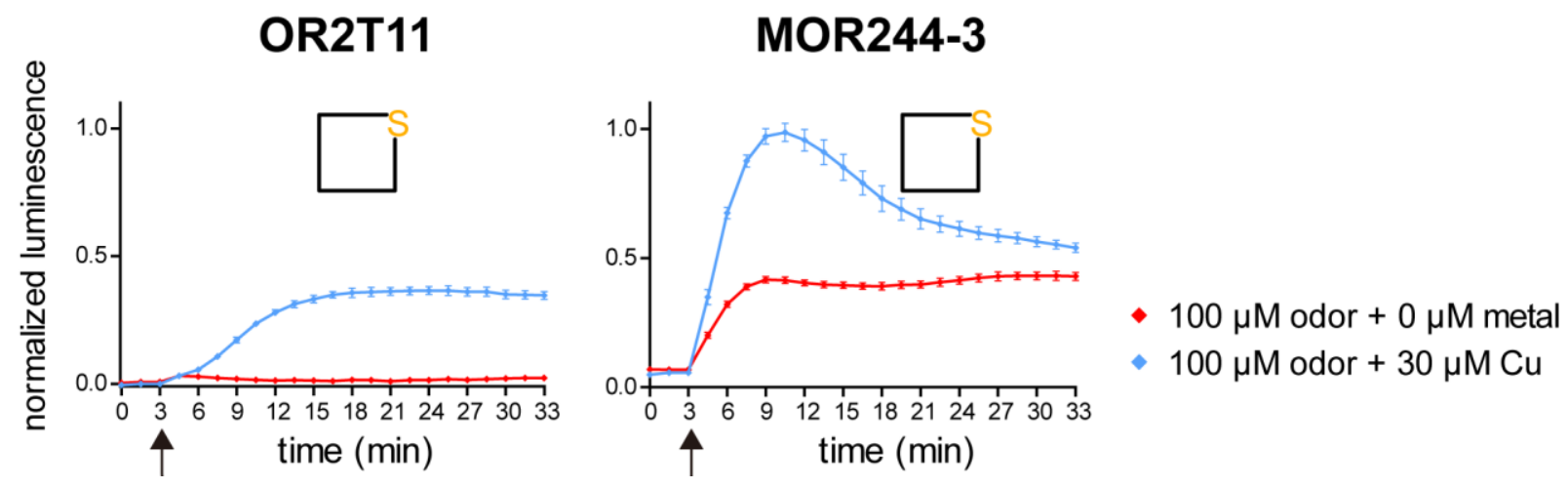

Figure S7. Both OR2T11 and MOR244-3 respond to thietane in the GloSensor ${ }^{\mathrm{TM}}$ cAMP assay. Real-time measurement of OR2T11 and MOR244-3 activation in response to the small cyclic sulfide thietane as detected within 30 minutes of odorant addition. The arrow along the $x$-axis indicates the time point of odorant addition. $y$-axis indicates normalized luminescence $\pm \operatorname{SEM}(N=3)$. All responses are normalized to the highest response of OR2T11 to TBM and MOR244-3 to MTMT, respectively. 


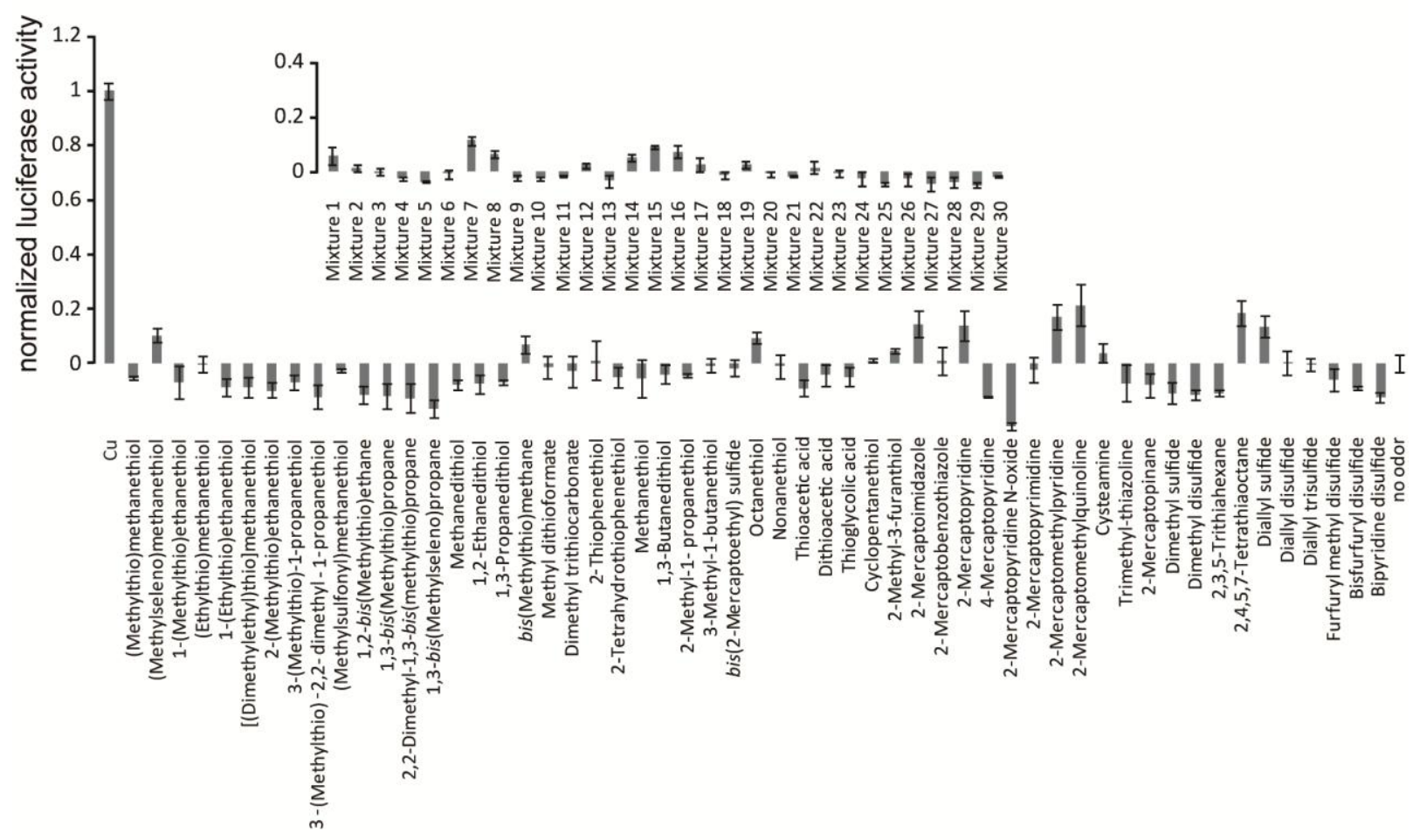

Figure S8. Screening for MOR244-2 ligands. The responses of MOR244-2 to 55 thiol ligands and a panel of 30 mixtures (inset). The concentration used for 55 thiols and each component of the 30 mixtures was $30 \mu \mathrm{M}$, except for one thiol, 2-mercaptopyridine $N$-oxide, which exhibited cell toxicity at $30 \mu \mathrm{M}$ and was used at $5 \mu \mathrm{M}$ instead. All responses were normalized to the response of MOR244-2 to $\mathrm{CuCl}_{2}$ at $100 \mu \mathrm{M}(N=3)$. See SI Table S3 for detailed information on the 30 mixtures. 

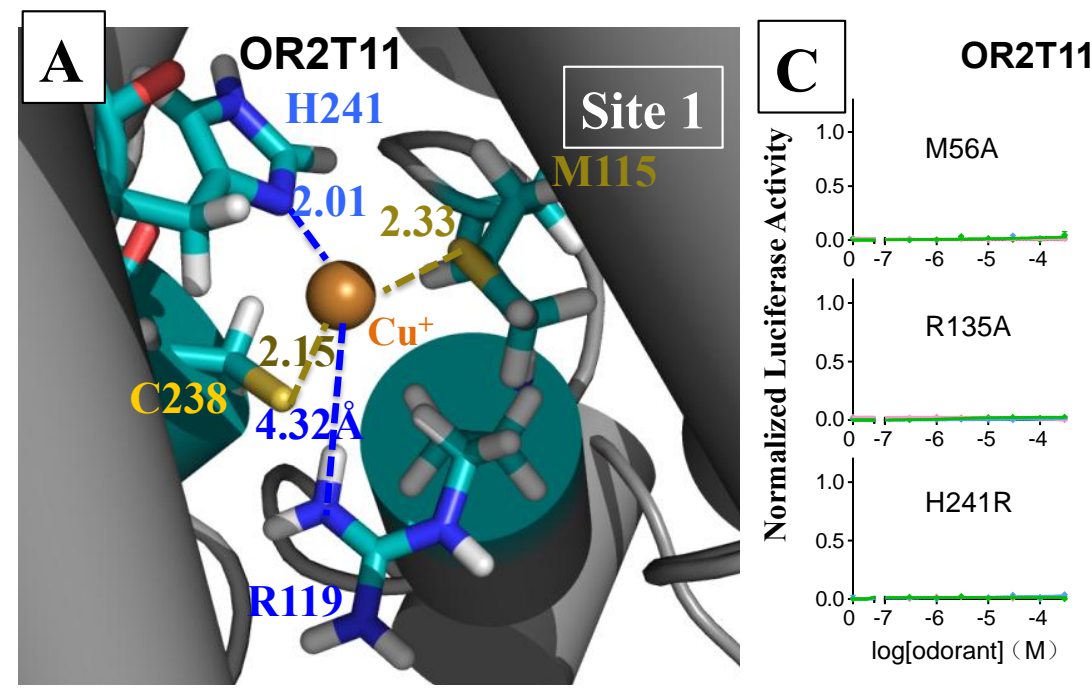

metal effect
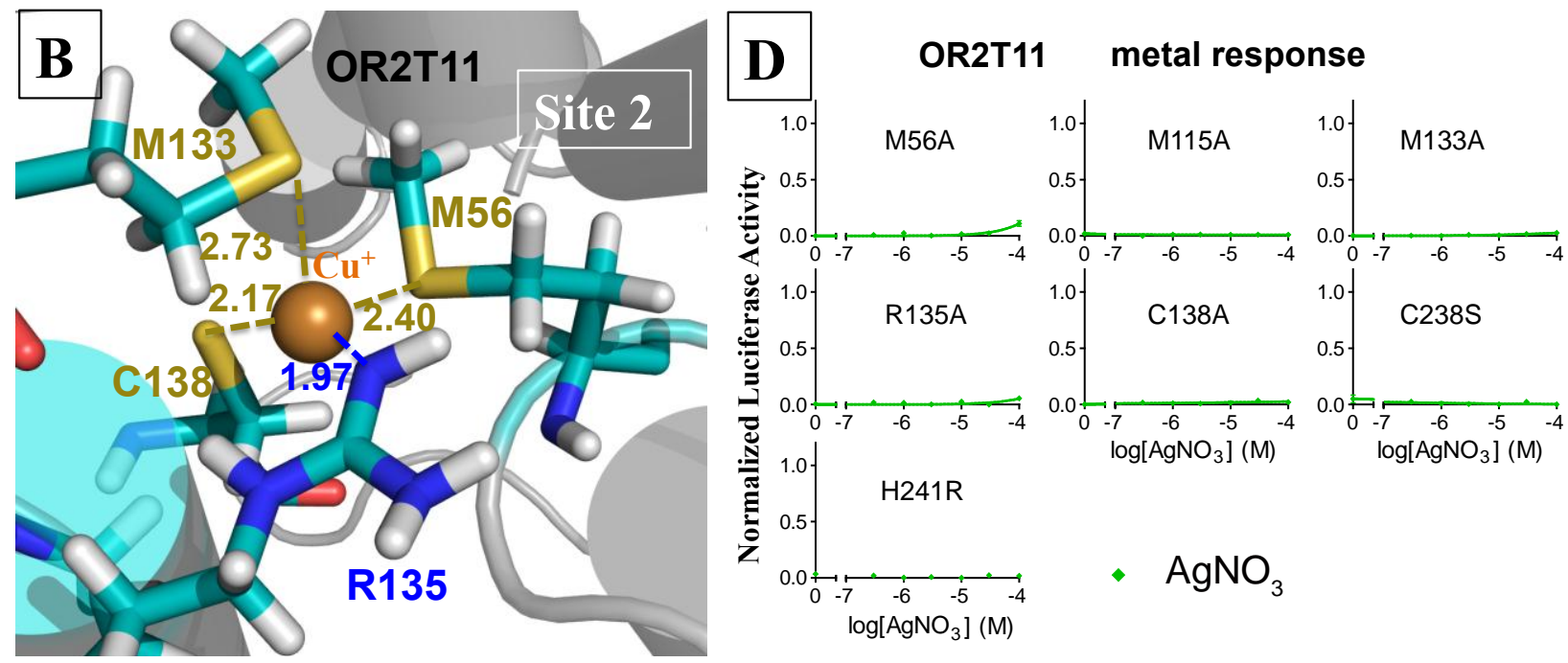

Figure S9. Binding sites of OR2T11. (A) and (B) show the two binding sites of OR2T11 consisting of M115, C238 and H241, and M56, M133, R135 and C138, respectively. (C) and (D) show the mutagenesis studies on the corresponding amino acid residues in the binding site of OR2T11. The cysteine is in thiolate form. 

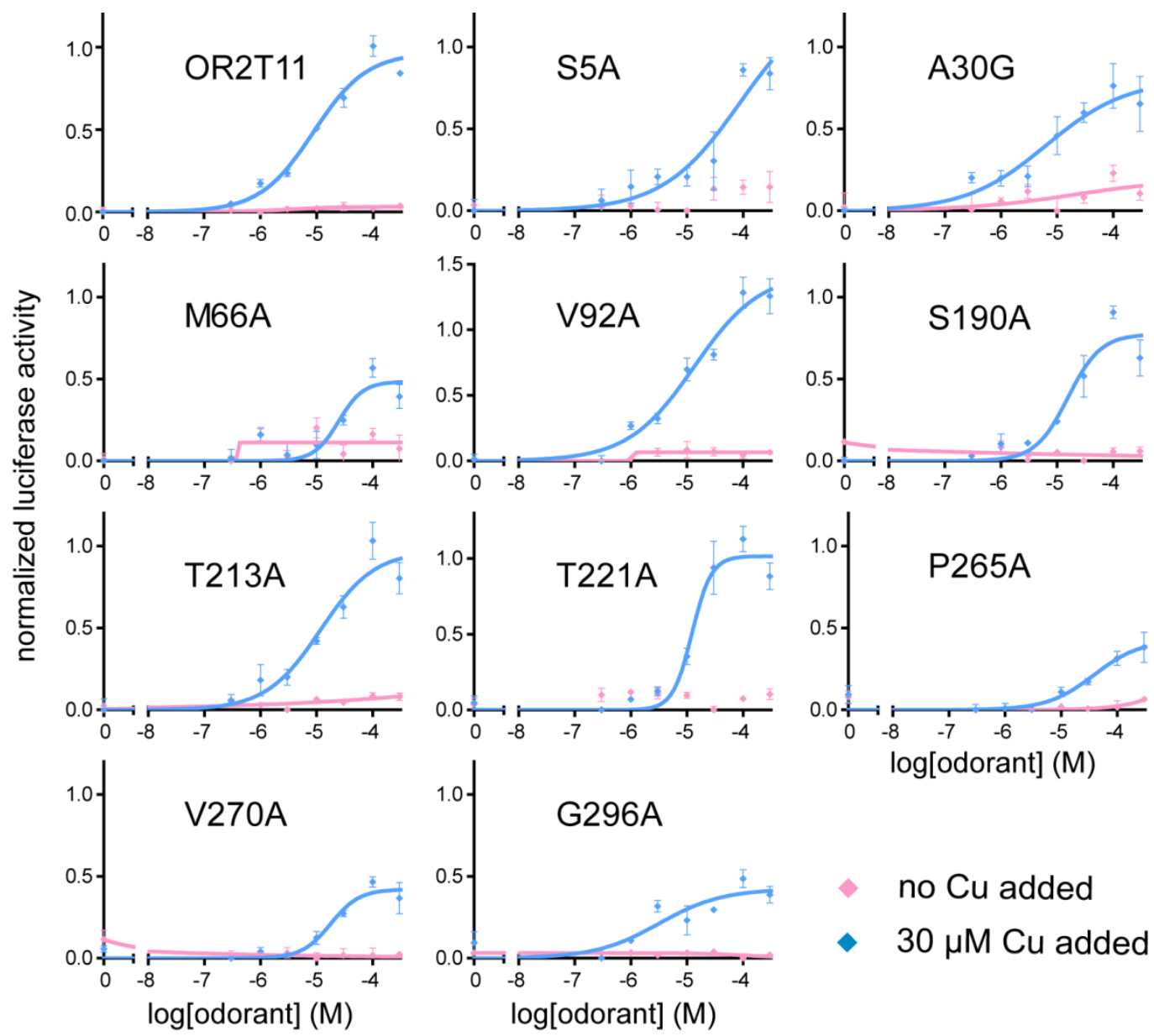

Figure S10. OR2T11 control mutants. Dose-response curves of OR2T11 control mutants to TBM. The $y$-axis indicates normalized response $\pm \operatorname{SEM}(N=3)$. All responses are normalized to the highest response of wild type OR2T11 to TBM with $30 \mu \mathrm{M}$ of $\mathrm{Cu}$ added. 

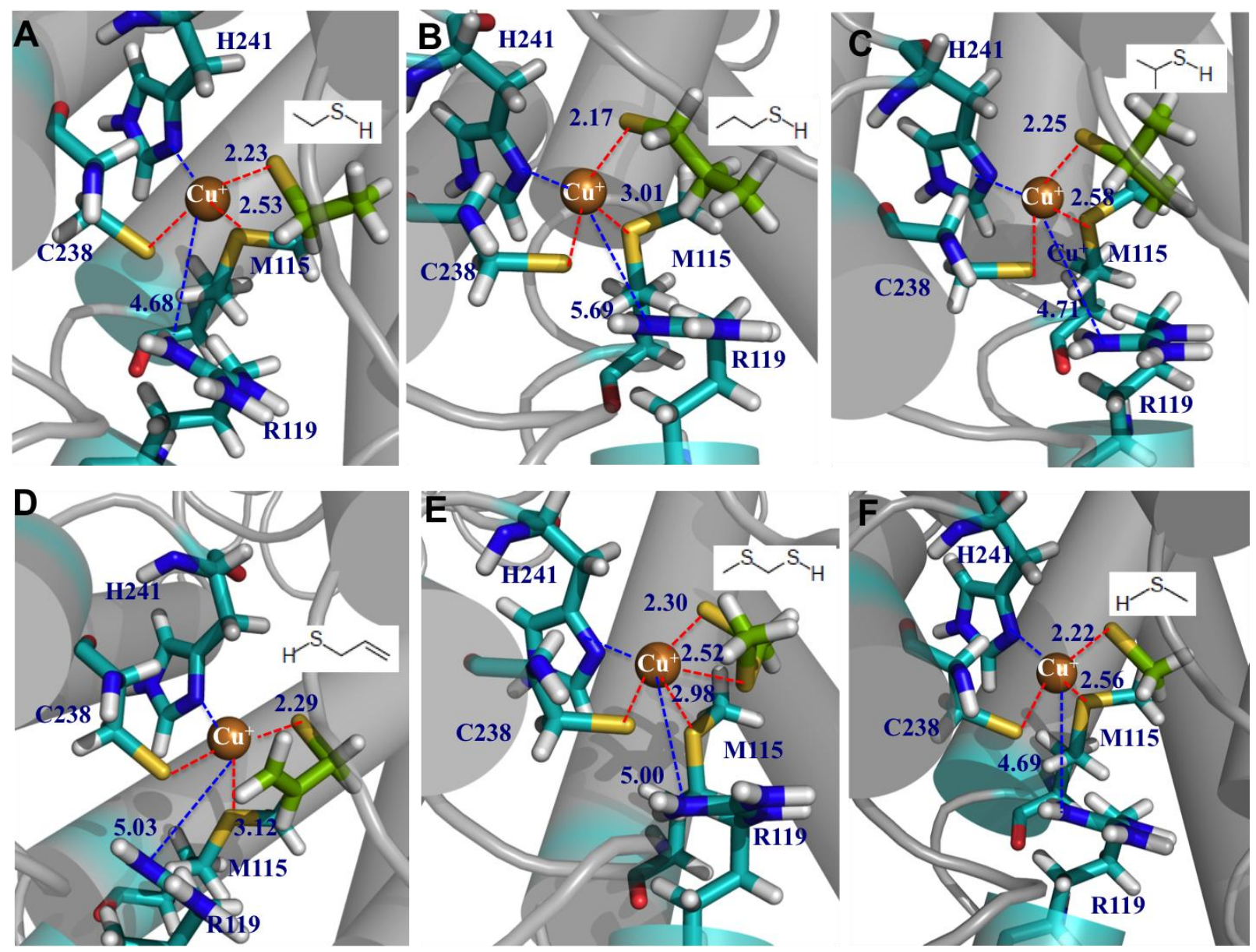

Figure S11. QM/MM optimized models of (A) EtSH, (B) $n$-PrSH, (C) $i$-PrSH, (D) 2-propenethiol, (E) (methylthio)methanethiol, and (F) methanethiol, all bound to the $\mathrm{Cu}^{+}$ion in the OR2T11 site consisting of M115, C238 and H241. The cysteine and ligands are in the thiolate form. 

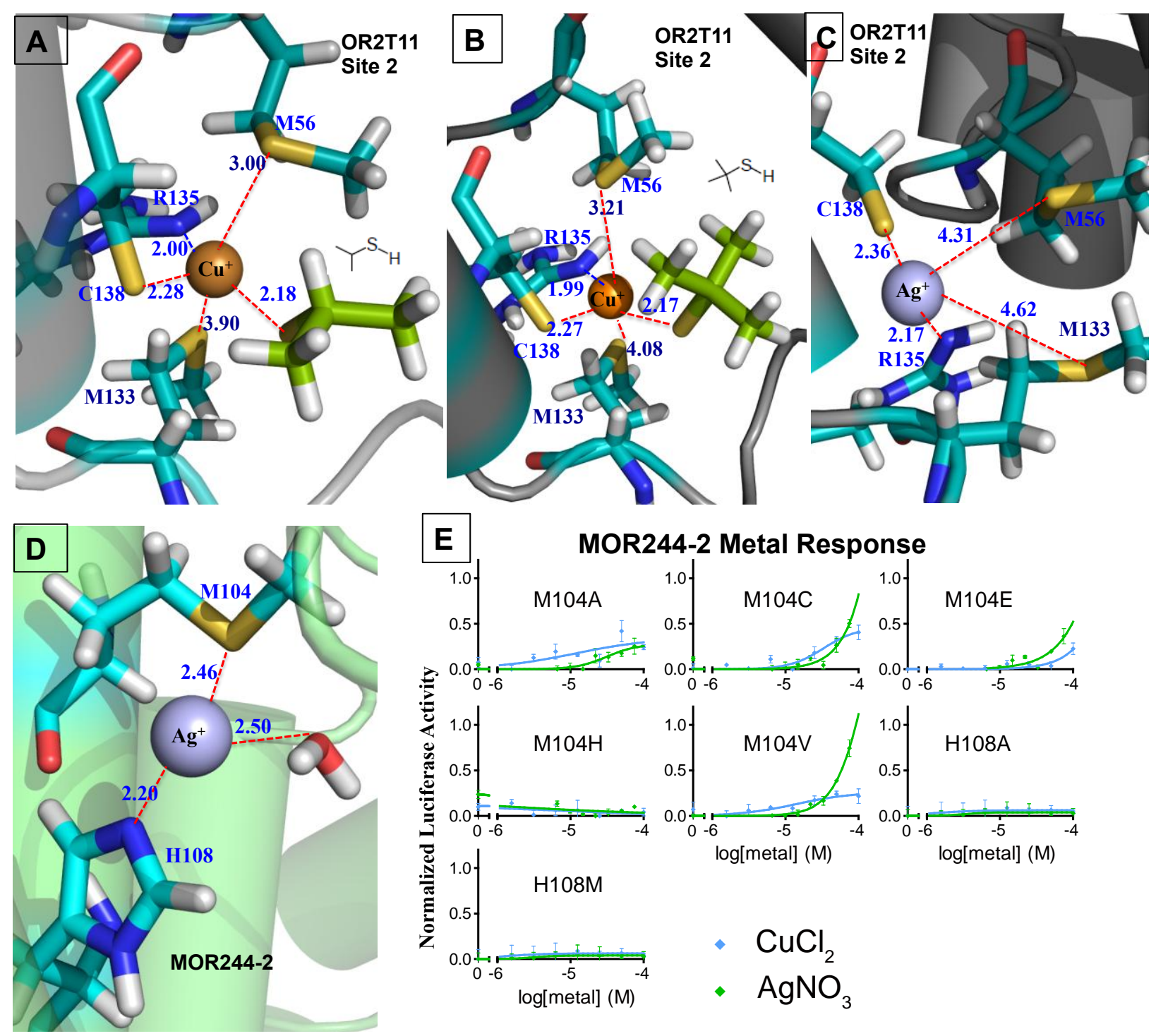

Figure S12. QM/MM optimized models of (A) $\boldsymbol{i}$-PrSH and (B) $\boldsymbol{t}$-BuSH bound to copper ion in Site 2 of OR2T11. The coordination of the silver ion to the heteroatoms of (C) M56, M133, R135, and C138 in OR2T11 and (D) M104, H108, and water molecule in MOR244-2. (E) The response of silver ion to MOR244-2. The cysteine and ligands are in thiolate form. 


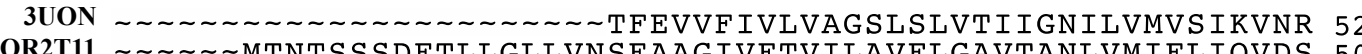
MOR244-3 MARA MOR244-2 MEKAVLINETSVMSFRLTGLSTNPLVQMAVFFIFLIFYVLTLVGNILIVITIIYDR 56

3UON HLQTVNNYFLFSLACADLIIGVFSMNLYTLYTVIGYWPLGPVVCDLWLALDYVVSN 108

OR2T11 RLHTPMYFLLSQLSIMDTLFICTTVPKLLADMVSKEKIISFVACGIQIFLYLTMIG 106 MOR244-3 RLHNPMYFFLSNLSFIDICHSSVTVPKMLEGLLLERKTISFDNCIAOLFFLHLFAC 109 MOR244-2 RLHTPMYFFLSNLSFIDVCHSTVTVPKMLSDTFSEEKLISFDACVVQMFFLHLFAC 112

3UON ASVMNLLIISFDRYFCVTKPT YPVKRTTKMAGMMIAAAWVLS FILWAPAILFW 162 OR2T11 SEFFLLGLMAYDRYVAVCNPLRYPVLMNRKKCLLLAAGAWFGGSLDGFLLTPITMN 162 MOR244-3 SEIFLLTIMAYDRYVAICIPLHYSNVMNMKVCVQLVFALWLGGTIHSLVQTFLTIR 165 MOR244-2 TEIFLLTVMAYDRYVAICKPLQYMTIMNWKVCMMLAAALWTGGTIHSISLTSLTIK 168

3UON QFIVGVRTVEDGECYIQFFSNAAVTFGTAIAAFYLP VIIMTVLYWHISRASKSRI 217 OR2T11 VPYCGSRSINHFFCEIPAVLKLACADTSLYETLMYICCVLMLLIPISIISTSYSLI 218 MOR244-3 LPYCGPNIIDSYFCDVPPVIKLACTDTYLTGILIVSNSGTISLVCFLALVTSYTVI 221 MOR244-2 LPYCGPDEIDNFFCDVPQVIKLACTDTHIIEILIVSNSGLISVVCFVVLVVSYAVI 224

3UON PPSREKKVTRTILAILLAFIITWAPYNVMVLINTFCAPCIPNTVWT IGYW 427 OR2T11 LLTIHRMPSAEGRKKAFTTCSSHLTVVSIFYGAAFYTYVLPQSFHTPEQDKVVSAF 274 MOR244-3 LFSLRKK SAEGRRKALSTCSAHFMVVTLFFGPCIFLYTRPDSSFS IDKVVSVF 274 MOR244-2 LVSLRQQ ISDGKRKALSTCAAHLTVVTLFLGHCIFIYSRPSTSLP EDKVVSVF 277

3UON LCYINSTINPACYALCNATFKKTFKHLLM 456

OR2T11 YTIVTPMLNPLIYSLRNKDVIGAFKKVFACCSSAOKVATSDA 316

MOR244-3 YTVVTPLLNPLIYTLRNEEVKTAMKH 300

MOR244-2 FTAVTPLLNPIIYTLRNEDMKSALNKLIKRREK 310
\end{abstract}

Figure S13. Multiple sequence alignment of the human M2 muscarinic receptor, human olfactory receptor OR2T11, mouse olfactory receptor MOR244-3 and mouse olfactory receptor MOR244-2. 


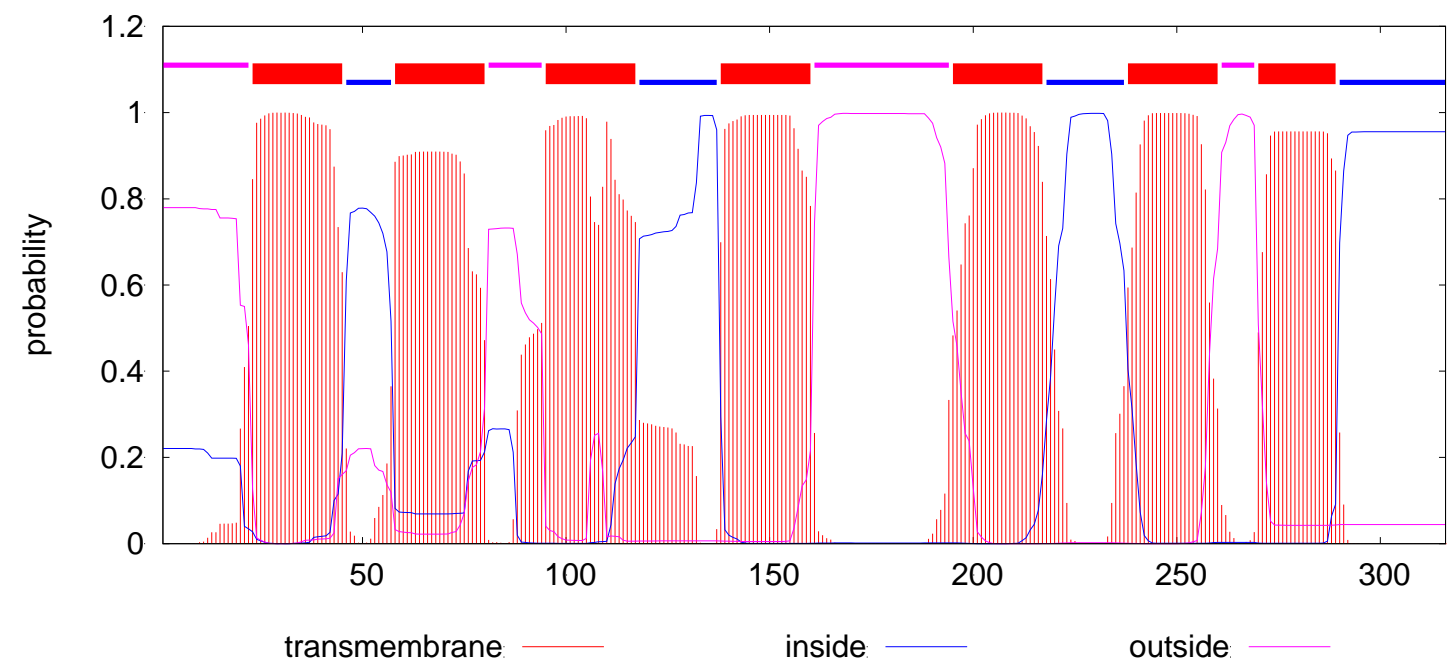

Figure S14. TMHMM posterior probabilities for OR2T11. Seven transmembrane regions are clearly indicated as red bar. 

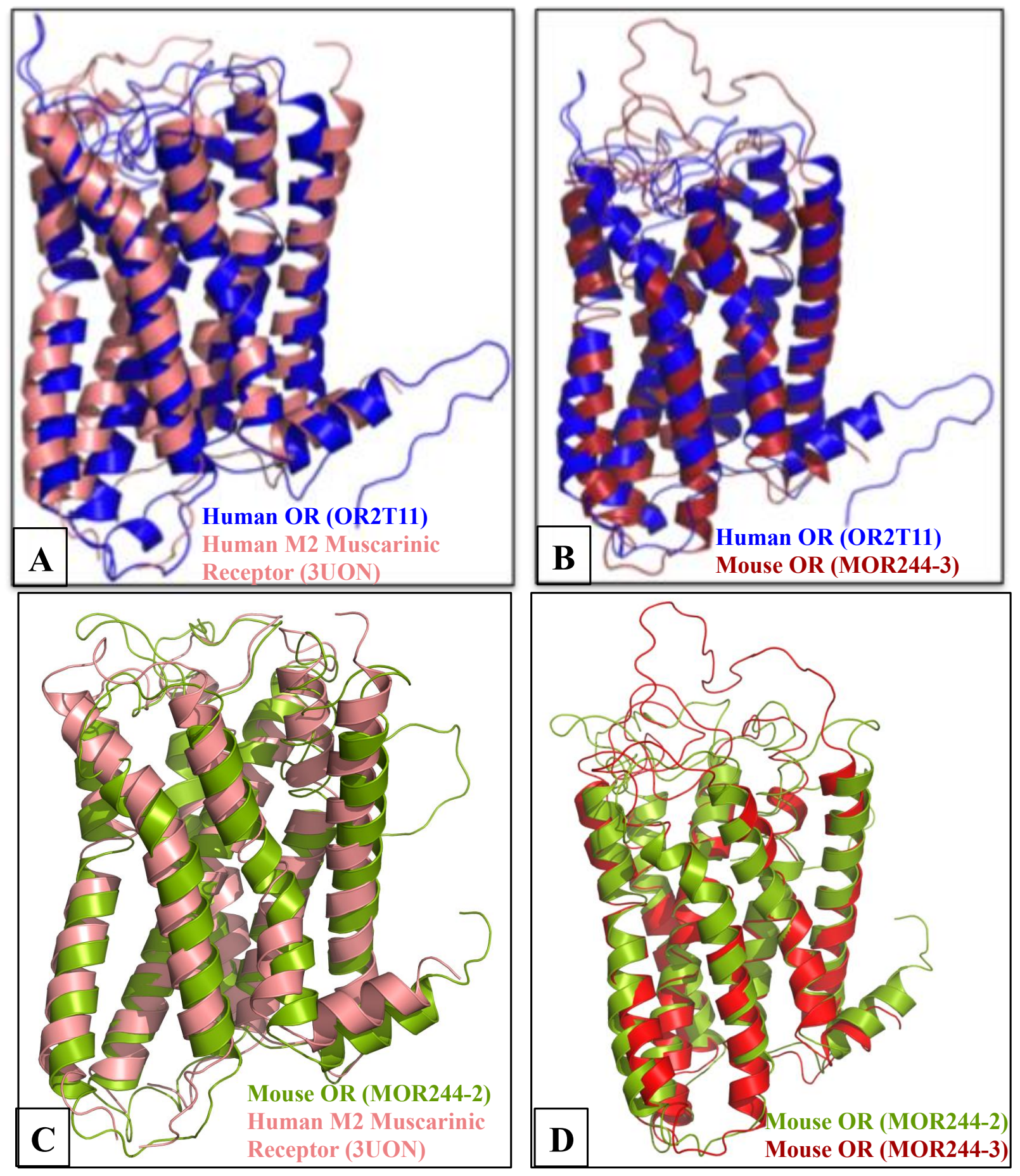

Figure S15. Multi sequence Stamp alignment of the seven TM regions of the homology model of OR2T11 (blue) with the human M2 muscarinic receptor (reddish pink) (A), and the mouse olfactory receptor MOR244-3 (red) (B). Superposition of the homology model of the mouse olfactory receptor MOR244-2 (green) with the human M2 muscarinic receptor (reddish pink) (C), and superimposed to the mouse olfactory receptor MOR244-3 (red) (D). 


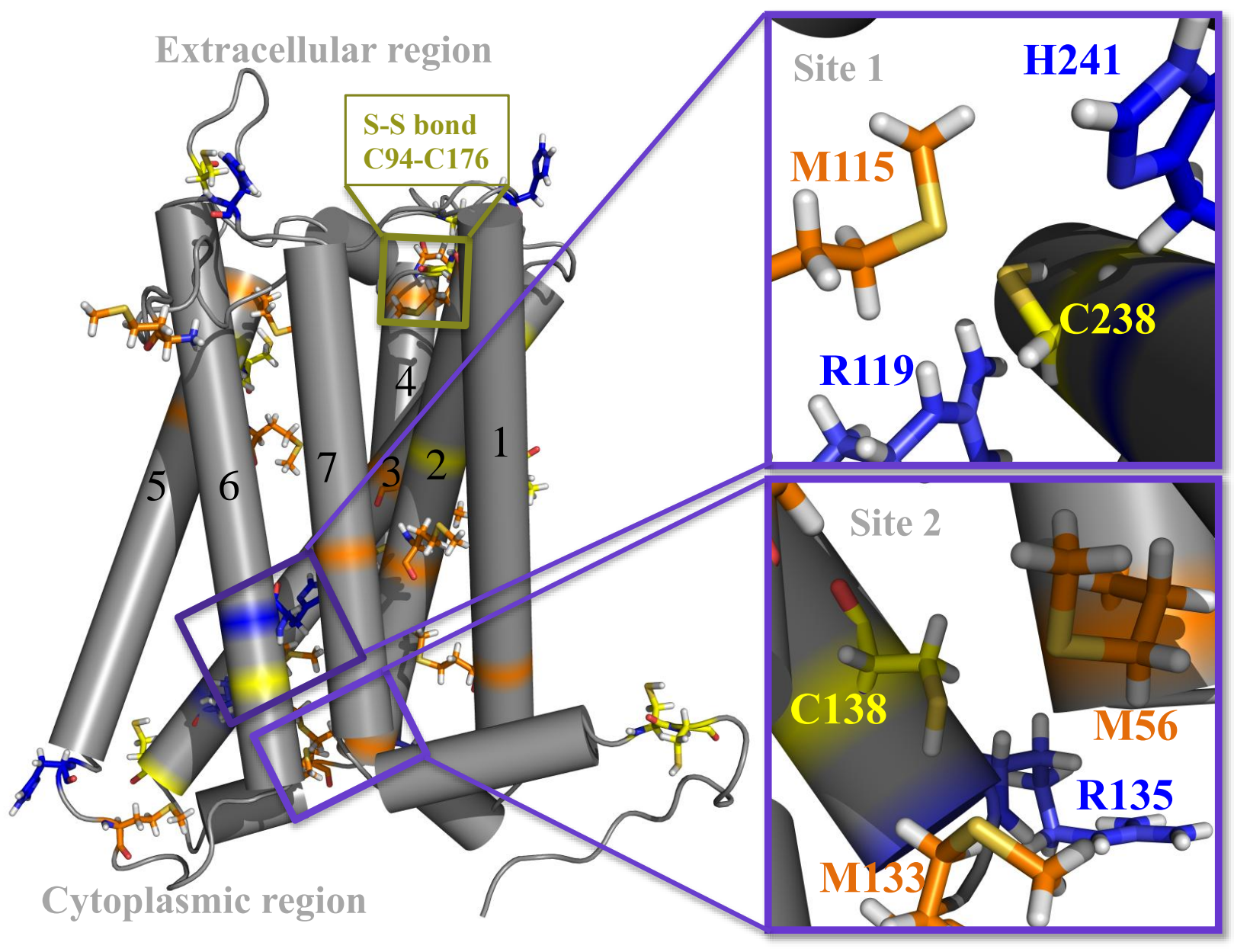

Figure S16. Predicted metal binding sites in OR2T11, including site 1 (M115, C238 and H241) and site 2 (M56, M133, R135 and C138). 


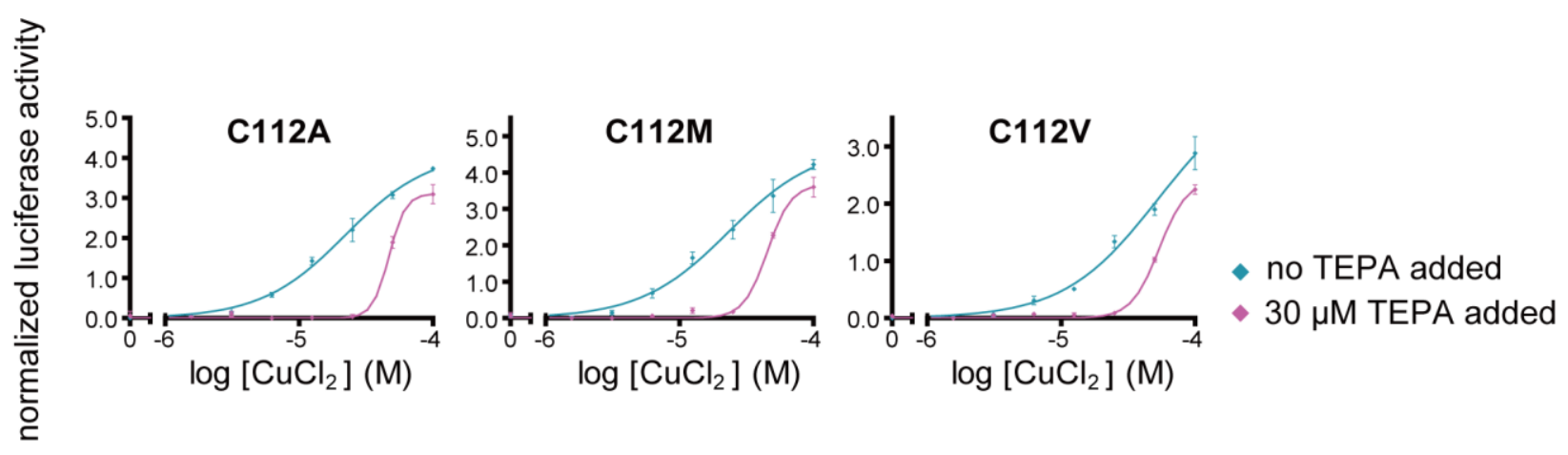

Figure S17. The response of MOR244-2 C112 mutants (C112A, C112M and C112V) to copper. The $y$-axis indicates normalized response $\pm \operatorname{SEM}(N=3)$. The responses are normalized to the highest response of the wild type receptor. 


\section{Supporting Tables}

Table S1. A list of sulfur-containing compounds used on OR2T11 and MOR244-3.

\begin{tabular}{|c|c|c|c|}
\hline IUPAC name & CAS\# & structure & source \\
\hline sodium sulfide $(\mathrm{Na}(\mathrm{SH}))$ & $16721-80-5$ & & Adamas \\
\hline sodium thiomethoxide & $5188-07-8$ & & Sigma-Aldrich \\
\hline ethanethiol & $75-08-1$ & & Adamas \\
\hline propane-1-thiol & $107-03-9$ & & Adamas \\
\hline propane-2-thiol & $75-33-2$ & & Adamas \\
\hline 2-methylpropane-2-thiol & $75-66-1$ & & Sigma-Aldrich \\
\hline 2-methylpropane-1-thiol & 513-44-0 & & Sigma-Aldrich \\
\hline butane-2-thiol & $513-53-1$ & & Sigma-Aldrich \\
\hline 3-methylbutane-2-thiol & $2084-18-6$ & & Adamas \\
\hline prop-2-ene-1-thiol & $870-23-5$ & & Sigma-Aldrich \\
\hline cyclopentanethiol & $1679-07-8$ & & Sigma-Aldrich \\
\hline (methylthio)methanethiol & $29414-47-9$ & & in-house synthesis \\
\hline (ethylthio)methanethiol & $29414-49-1$ & & In-house synthesis \\
\hline 1-(methylthio)ethanethiol & $31331-53-0$ & & in-house synthesis \\
\hline thiolane-2-thiol & $61477-08-5$ & & in-house synthesis \\
\hline 2,3,5-trithiahexane & $42474-44-2$ & & in-house synthesis \\
\hline bis(methylthiomethyl) disulfide & 85544-38-3 & & in-house synthesis \\
\hline butane-1-thiol & $109-79-5$ & & Sigma-Aldrich \\
\hline pentane-1-thiol & $110-66-7$ & & $\mathrm{~J} \& \mathrm{~K}$ \\
\hline hexane-1-thiol & $111-31-9$ & & Sigma-Aldrich \\
\hline heptane-1-thiol & $1639-09-4$ & & $\mathrm{~J} \& \mathrm{~K}$ \\
\hline
\end{tabular}




\begin{tabular}{|c|c|c|c|}
\hline octane-1-thiol & $111-88-6$ & 1 & Sigma-Aldrich \\
\hline nonane-1-thiol & $1455-21-6$ & H & Sigma-Aldrich \\
\hline decane-1-thiol & $143-10-2$ & & Sigma-Aldrich \\
\hline thietane & $287-27-4$ & & in-house synthesis \\
\hline propane-1,3-dithiol & $109-80-8$ & & in-house synthesis \\
\hline butane-1,4-dithiol & $1191-08-8$ & & Sigma-Aldrich \\
\hline pentane-1,5-dithiol & $928-98-3$ & $\mathrm{H}_{\mathrm{S}}$ & Sigma-Aldrich \\
\hline hexane-1,6-dithiol & $1191-43-1$ & & Sigma-Aldrich \\
\hline octane-1,8-dithiol & $1191-62-4$ & $\mathrm{H}^{-\mathrm{S}}$ & Sigma-Aldrich \\
\hline 3-methylbutane-1-thiol & $541-31-1$ & & Sigma-Aldrich \\
\hline pentane-2-thiol & 2084-19-7 & & FluoroChem \\
\hline 2-methylbutane-1-thiol & $1878-18-8$ & & Sigma-Aldrich \\
\hline methanedithiol & $6725-64-0$ & & in-house synthesis \\
\hline ethane-1,2-dithiol & $540-63-6$ & & Sigma-Aldrich \\
\hline
\end{tabular}


Table S2. $\mathrm{EC}_{50}$ deduced from the dosage response curves for OR2T11 and MOR244-3 in the luciferase assay without (first row) and with (second row) copper. Values are given in $\mu \mathrm{M}$.

\begin{tabular}{|c|c|c|}
\hline odorant & OR2T11 & MOR244-3 \\
\hline \multirow{2}{*}{ ethanethiol } & $>100$ & $>100$ \\
\hline & 24.0 & $>100$ \\
\hline \multirow{2}{*}{ propane-1-thiol } & $>100$ & $>100$ \\
\hline & 6.1 & $>100$ \\
\hline \multirow{2}{*}{ propane-2-thiol } & $>100$ & $>100$ \\
\hline & 7.4 & $>100$ \\
\hline \multirow{2}{*}{ 2-methylpropane-2-thiol } & $>100$ & $>100$ \\
\hline & 13.1 & $>100$ \\
\hline \multirow{2}{*}{ 2-methylpropane-1-thiol } & $>100$ & $>100$ \\
\hline & 9.1 & $>100$ \\
\hline \multirow{2}{*}{ butane-2-thiol } & $>100$ & $>100$ \\
\hline & 8.9 & $>100$ \\
\hline \multirow{2}{*}{ 3-methylbutane-2-thiol } & $>100$ & $>100$ \\
\hline & 28.2 & $>100$ \\
\hline \multirow{2}{*}{ prop-2-ene-1-thiol } & $>100$ & $>100$ \\
\hline & 1.6 & $>100$ \\
\hline \multirow{2}{*}{ (methylthio)methanethiol } & $>100$ & 20.0 \\
\hline & 2.2 & 1.0 \\
\hline \multirow{2}{*}{ 1-(methylthio)ethanethiol } & $>100$ & 27.3 \\
\hline & 1.2 & 2.2 \\
\hline \multirow{2}{*}{ thiolane-2-thiol } & $>100$ & 3.2 \\
\hline & 2.5 & 0.5 \\
\hline \multirow{2}{*}{ 2,3,5-trithiahexane } & $>100$ & 5.3 \\
\hline & 18.2 & 5.4 \\
\hline \multirow{2}{*}{ bis(methylthiomethyl) disulfide } & $>100$ & 1.8 \\
\hline & 2.0 & 0.4 \\
\hline
\end{tabular}


Table S3. A list of compounds in the mixture panel screened on MOR244-2 in Figure S8.

\begin{tabular}{|c|c|c|}
\hline mixture\# & IUPAC name & CAS\# \\
\hline \multirow{6}{*}{1} & chromen-2-one & $91-64-5$ \\
\hline & 1-phenylethanone & $98-86-2$ \\
\hline & 2-pentyl-3-methyl-2-cyclopenten-1-one & $1128-08-1$ \\
\hline & cyclohexanone & $108-94-1$ \\
\hline & $(1 S, 4 S)-1,7,7$-trimethylbicyclo[2.2.1]heptan-2-one & $464-48-2$ \\
\hline & $(1 R, 4 R)$-1,7,7-trimethylbicyclo[2.2.1]heptan-2-one & $464-49-3$ \\
\hline \multirow{6}{*}{2} & diphenylmethanone & $119-61-9$ \\
\hline & 2-methyl-5-prop-1-en-2-ylcyclohexan-1-one & $7764-50-3$ \\
\hline & nonan-2-one & $821-55-6$ \\
\hline & heptan-3-one & $106-35-4$ \\
\hline & heptan-2-one & $110-43-0$ \\
\hline & hexane-3,4-dione & $4437-51-8$ \\
\hline \multirow{6}{*}{3} & 2-methyl-5-prop-1-en-2-ylcyclohexan-1-one & $5524-05-0$ \\
\hline & 4-hydroxy-2,3-di(methyl)-2H-furan-5-one & $81-14-1$ \\
\hline & $(1 R, 4 S)$-1,3,3-trimethylbicyclo[2.2.1] heptan-2-one & $7787-20-4$ \\
\hline & butan-2-one & 78-93-3 \\
\hline & 1-phenylpropane-1,2-dione & $579-07-7$ \\
\hline & (5S)-2-methyl-5-prop-1-en-2-ylcyclohex-2-en-1-one & $2244-16-8$ \\
\hline \multirow{4}{*}{4} & $(1 S, 4 R)$-1,3,3-trimethylbicyclo[2.2.1]heptan-2-one & $4695-62-9$ \\
\hline & (R)-5-methyl-2-(propan-2-ylidene)cyclohexan-1-one & $89-82-7$ \\
\hline & $(2 S, 5 R)$-5-methyl-2-propan-2-ylcyclohexan-1-one & $14073-97-3$ \\
\hline & 7-hydroxychromen-2-one & $93-35-6$ \\
\hline \multirow{6}{*}{5} & nonanoic acid & $112-05-0$ \\
\hline & octanoic acid & $124-07-2$ \\
\hline & decanoic acid & $334-48-5$ \\
\hline & heptanoic acid & $111-14-8$ \\
\hline & 4-hydroxy-3-methoxybenzoic acid & $121-34-6$ \\
\hline & propanoic acid & 79-09-4 \\
\hline \multirow{6}{*}{6} & heptanedioic acid & $111-16-0$ \\
\hline & 6-bromohexanoic acid & $4224-70-8$ \\
\hline & (2S)-2-phenylbutanoic acid & $4286-15-1$ \\
\hline & (E)-3-phenylprop-2-enoic acid & $140-10-3$ \\
\hline & 10-bromodecanoic acid & $50530-12-6$ \\
\hline & 5-bromopentanoic acid & $2067-33-6$ \\
\hline \multirow{3}{*}{7} & butanoic acid & $107-92-6$ \\
\hline & 2-sulfanylacetic acid & $68-11-1$ \\
\hline & hexanoic acid & $142-62-1$ \\
\hline
\end{tabular}




\begin{tabular}{|c|c|c|}
\hline & 2-methylpropanoic acid & $79-31-2$ \\
\hline & 3-methylbutanoic acid & $503-74-2$ \\
\hline & 4-methylpentanoic acid & $646-07-1$ \\
\hline \multirow{5}{*}{8} & hexane-1-thiol & $111-31-9$ \\
\hline & (methylseleno)methanethiol & $\mathrm{N} / \mathrm{A}$ \\
\hline & octane-1-thiol & $111-88-6$ \\
\hline & 1,1-dioxothiolane-3-thiol & $61477-08-5$ \\
\hline & ethylsulfanylmethanethiol & 29414-49-1 \\
\hline \multirow{5}{*}{9} & 3-methylbut-2-enyl acetate & $1191-16-8$ \\
\hline & ethyl 2-methylpropanoate & $97-62-1$ \\
\hline & butyl formate & $592-84-7$ \\
\hline & prop-2-enyl 2-phenylacetate & $1797-74-6$ \\
\hline & [(2E)-3,7-dimethylocta-2,6-dienyl] acetate & $105-87-3$ \\
\hline \multirow{6}{*}{10} & butyl acetate & $123-86-4$ \\
\hline & 2-(4-methylcyclohex-3-en-1-yl)propan-2-yl acetate & $80-26-2$ \\
\hline & (1-butoxy-1-oxopropan-2-yl) butanoate & $7492-70-8$ \\
\hline & hexyl butanoate & $2639-63-6$ \\
\hline & methyl 2-hydroxybenzoate & $119-36-8$ \\
\hline & ethyl 2-oxopropanoate & $617-35-6$ \\
\hline \multirow{6}{*}{11} & [(2Z)-3,7-dimethylocta-2,6-dienyl] 2-methylpropanoate & $2345-24-6$ \\
\hline & octyloctanoate & $2306-88-9$ \\
\hline & oxacyclohexadecan-2-one & $106-02-5$ \\
\hline & 3-methylbutyl octanoate & 2035-99-6 \\
\hline & 3-phenylpropyl propanoate & $122-74-7$ \\
\hline & (2-methoxy-4-prop-2-enylphenyl) acetate & $93-28-7$ \\
\hline \multirow{6}{*}{12} & decanal & $112-31-2$ \\
\hline & octanal & $124-13-0$ \\
\hline & 3-(4-tert-butylphenyl)propanal & $18127-01-0$ \\
\hline & 3-ethoxy-4-hydroxybenzaldehyde & $121-32-4$ \\
\hline & 2-phenylacetaldehyde & $122-78-1$ \\
\hline & 4-(4-hydroxy-4-methylpentyl)cyclohex-3-ene-1-carbaldehyde & 31906-04-4 \\
\hline \multirow{6}{*}{13} & benzo[a]pyrene & $50-32-8$ \\
\hline & pyrene & $129-00-0$ \\
\hline & fluoranthene & $206-44-0$ \\
\hline & acenaphthylene & $83-32-9$ \\
\hline & 9-methylcarbazole & 1484-12-4 \\
\hline & 1-methylindole & $603-76-9$ \\
\hline \multirow{4}{*}{14} & 4,6,6-trimethylbicyclo[3.1.1]heptane-4-thiol & $23832-18-0$ \\
\hline & 3-methylbutane-1-thiol & $541-31-1$ \\
\hline & thiophene-2-thiol & $7774-74-5$ \\
\hline & 2-(2-sulfanylethylsulfanyl)ethanethiol & $3570-55-6$ \\
\hline
\end{tabular}




\begin{tabular}{|c|c|c|}
\hline & 1-[(1,1-dimethylethyl)thio]methanethiol & $722541-95-9$ \\
\hline & 3-(methylthio)-1-propanethiol & $26718-09-2$ \\
\hline \multirow{6}{*}{15} & 2,2-dimethyl-3-(methylthio)propane-1-thiol & $1519309-92-2$ \\
\hline & pyridin-2-ylmethanethiol & $2044-73-7$ \\
\hline & 2-methylpropane-2-thiol & $75-66-1$ \\
\hline & decane-1,10-dithiol & $1191-67-9$ \\
\hline & 2-naphthalen-1-yloctane-1,8-dithiol & $1191-62-4$ \\
\hline & 2-methylbutane-1-thiol & $1878-18-8$ \\
\hline \multirow{6}{*}{16} & butane-1,4-dithiol & $1191-08-8$ \\
\hline & nonane-1,9-dithiol & $3489-28-9$ \\
\hline & hexane-1,6-dithiol & $1191-43-1$ \\
\hline & 2-methyloctane-2-thiol & $25360-10-5$ \\
\hline & propane-1,3-dithiol & $109-80-8$ \\
\hline & decane-1-thiol & $143-10-2$ \\
\hline \multirow{6}{*}{17} & pentane-1,5-dithiol & $928-98-3$ \\
\hline & butane-2-thiol & $513-53-1$ \\
\hline & pentane-2-thiol & 2084-19-7 \\
\hline & 3-methylbutane-2-thiol & $2084-18-6$ \\
\hline & prop-2-ene-1-thiol & $870-23-5$ \\
\hline & propane-1,3-dithiol & $109-80-8$ \\
\hline \multirow{6}{*}{18} & propan-1-ol & $71-23-8$ \\
\hline & propan-2-ol & $67-63-0$ \\
\hline & 2-methylpropan-2-ol & $75-65-0$ \\
\hline & 2-methylpropan-1-ol & $78-83-1$ \\
\hline & butan-2-ol & $78-92-2$ \\
\hline & 3-methylbutan-2-ol & $598-75-4$ \\
\hline \multirow{6}{*}{19} & (methyldisulfanyl)methane & $624-92-0$ \\
\hline & bis(methylsulfanyl)methane & $1618-26-4$ \\
\hline & 3-(prop-2-enyltrisulfanyl)prop-1-ene & $2050-87-5$ \\
\hline & methylsulfanyl-(methylsulfanylmethyldisulfanyl)methane & $85544-38-3$ \\
\hline & 2-[(pyridin-2-ylmethyldisulfanyl)methyl]pyridine & $2127-04-0$ \\
\hline & 2,2-dimethyl-1,3-bis(methylthio)propane & 71870-73-0 \\
\hline \multirow{6}{*}{20} & thietane & $287-27-4$ \\
\hline & 2-methylsulfanylbutane & $10359-64-5$ \\
\hline & 1-methylsulfanyloctane & $3698-95-1$ \\
\hline & 1-methylsulfanylpentane & $1741-83-9$ \\
\hline & 1-methylsulfanyldecane & $22438-39-7$ \\
\hline & 1-methylsulfanylbutane & $628-29-5$ \\
\hline \multirow{3}{*}{21} & (ethyldisulfanyl)ethane & $110-81-6$ \\
\hline & 2-[(furan-2-ylmethyldisulfanyl)methyl]furan & $4437-20-1$ \\
\hline & 2-[(methyldisulfanyl)methyl]furan & $57500-00-2$ \\
\hline
\end{tabular}




\begin{tabular}{|c|c|c|}
\hline & 3-prop-2-enylsulfanylprop-1-ene & $592-88-1$ \\
\hline & phenoxybenzene & $101-84-8$ \\
\hline & 1,2-dimethoxy-4-prop-2-enylbenzene & $93-15-2$ \\
\hline \multirow{6}{*}{22} & (2E)-3,7-dimethylocta-2,6-dienal & $5392-40-5$ \\
\hline & 3,7-dimethyloct-6-enal & $106-23-0$ \\
\hline & heptanal & $111-71-7$ \\
\hline & 2-methylpropanal & $78-84-2$ \\
\hline & $(E)$-dec-2-enal & $3913-71-1$ \\
\hline & nonanal & $124-19-6$ \\
\hline \multirow{3}{*}{23} & undecanal & $112-44-7$ \\
\hline & 4-hydroxy-3-methoxybenzaldehyde & $121-33-5$ \\
\hline & (E)-3-phenylprop-2-enal & $14371-10-9$ \\
\hline \multirow{3}{*}{24} & $(1 R, 2 S, 5 R)$-5-methyl-2-propan-2-ylcyclohexan-1-ol & $2216-51-5$ \\
\hline & $(1 S, 2 R, 5 S)$-5-methyl-2-propan-2-ylcyclohexan-1-ol & $15356-60-2$ \\
\hline & butan-1-ol & $71-36-3$ \\
\hline \multirow{7}{*}{25} & 1,4-dioxacycloheptadecane-5,17-dione & $105-95-3$ \\
\hline & heptyl acetate & $112-06-1$ \\
\hline & [(1R,3R,4R)-4,7,7-trimethyl-3-bicyclo[2.2.1]heptanyl] acetate & $125-12-2$ \\
\hline & octyl acetate & $112-14-1$ \\
\hline & butyl butanoate & $109-21-7$ \\
\hline & ethyl 2-hydroxybenzoate & $118-61-6$ \\
\hline & propan-2-yl $(E)$-2-methylbut-2-enoate & $1733-25-1$ \\
\hline \multirow{5}{*}{26} & 2-methoxy-4-prop-2-enylphenol & $97-53-0$ \\
\hline & 2-methoxy-4-[(E)-prop-1-enyl]phenol & $97-54-1$ \\
\hline & 2-methoxy-4-methylphenol & $93-51-6$ \\
\hline & 2-methoxyphenol & $90-05-1$ \\
\hline & benzenethiol & $108-98-5$ \\
\hline \multirow{6}{*}{27} & benzene & $71-43-2$ \\
\hline & naphthalene & $91-20-3$ \\
\hline & anthracene & $120-12-7$ \\
\hline & phenanthrene & $1985-1-8$ \\
\hline & $9 H$-fluorene & $86-73-7$ \\
\hline & 4,6,6,7,8,8-hexamethyl-1,3,4,7-tetrahydrocyclopenta[g]isochromene & $1222-05-5$ \\
\hline \multirow{6}{*}{28} & 2-phenylethanamine & 64-04-0 \\
\hline & $N, N$-dimethylmethanamine & $75-50-3$ \\
\hline & cyclohexanamine & $108-91-8$ \\
\hline & 3-methylbutan-1-amine & $107-85-7$ \\
\hline & 2-methylpropan-1-amine & $78-81-9$ \\
\hline & 3-methylsulfanylpropan-1-amine & $4104-45-4$ \\
\hline \multirow{2}{*}{29} & $\mathrm{~N}, \mathrm{~N}$-dimethylethanamine & $598-56-1$ \\
\hline & hexan-1-amine & $111-26-2$ \\
\hline
\end{tabular}




\begin{tabular}{|c|c|c|}
\multirow{4}{*}{} & butan-1-amine & $109-73-9$ \\
\cline { 2 - 3 } & phenylmethanamine & $100-46-9$ \\
\cline { 2 - 3 } & $N, N$-diethylethanamine & $121-44-8$ \\
\cline { 2 - 3 } & $4-N, 4-N$-dimethylbenzene-1,4-diamine & $1126-71-2$ \\
\hline \multirow{3}{*}{30} & $4-(2-$-aminoethyl)phenol & $51-67-2$ \\
\cline { 2 - 3 } & $3 H-1,3-$-benzothiazole-2-thione & $149-30-4$ \\
\cline { 2 - 3 } & $1 H$-pyridine-2-thione & $2637-34-5$ \\
\hline \hline
\end{tabular}


Table S4. ONIOM extrapolated energies for QM/MM optimized structures, single point energy of odorants, and calculated binding energy for different thiols and hydrogen sulfide in the gas phase in the binding site of M115, C238 and H241.

\begin{tabular}{|c|c|c|c|}
\hline odorant & $\begin{array}{l}\text { ONIOM extrapolated } \\
\text { energy of the } \\
\text { complexes a.u }\end{array}$ & $\begin{array}{l}\text { single point } \\
\text { energy of } \\
\text { odorants a.u. }\end{array}$ & $\begin{array}{c}\text { binding } \\
\text { energy } \\
\left(\mathrm{kcal} \mathrm{mol}^{-1}\right)\end{array}$ \\
\hline methanethiol (MeSH) & -2480.422901 & -438.078609 & -30.3 \\
\hline ethanethiol (EtSH) & -2519.736399 & -477.387503 & -33.2 \\
\hline propane-1-thiol ( $n$-PrSH) & -2559.045017 & -516.694362 & -34.3 \\
\hline propane-2-thiol (i-PrSH) & -2559.048719 & -516.6979299 & -34.4 \\
\hline 3-methylbutane-2-thiol & -2637.630407 & -595.3139794 & -12.8 \\
\hline 2-methylpropane-2-thiol ( $t$-BuSH) & -2598.363506 & -556.009804 & -36.2 \\
\hline 2-methylpropane-1-thiol (i-BuSH) & -2598.33847 & -556.0070369 & -22.2 \\
\hline (methylthio)methanethiol (MTMT) & -2917.900232 & -875.5557832 & -30.4 \\
\hline butane-2-thiol (sec-BuSH) & -2598.342528 & -556.0059838 & -25.4 \\
\hline prop-2-ene-1-thiol (AlISH) & -2557.807195 & -515.4663709 & -28.1 \\
\hline hydrogen sulfide $\left(\mathrm{H}_{2} \mathrm{~S}\right)$ & -2441.118773 & -398.7834945 & -24.6 \\
\hline
\end{tabular}


Table S5. A list of primers used for OR2T11 and MOR244-2 mutagenesis.

OR2T11

\begin{tabular}{|c|c|}
\hline S5A F & 5'-ATGACGAACACAGCTTCCTCTGACTTCACCCTC-3' \\
\hline S5A R & 5'-GAGGGTGAAGTCAGAGGAGCTGTGTTCGTCAT-3' \\
\hline A30G F & 5'-TTTACAGTGATCCTTGGTGTTTTCTTGGGGGCC-3' \\
\hline A30G R & 5'-GGCCCCCAAGAAAACACCAAGGATCACTGTAAA-3' \\
\hline M56A F & 5'-TCGCCTCCACACCCCCGCGTACTTTCTGCTCAGTC-3' \\
\hline M56A R & 5'-GACTGAGCAGAAAGTACGCGGGGGTGTGGAGGCGA-3' \\
\hline M66A F & 5'-GTCAGCTGTCCATCGCGGACACCCTTTTCATCT-3' \\
\hline M66A R & 5'AGATGAAAAGGGTGTCCGCGATGGACAGCTGAC-3' \\
\hline V92A F & 5'AAGATCATTTCCTTTGCGGCCTGTGGCATCCAG-3' \\
\hline V92A R & 5'-CTGGATGCCACAGGCCGCAAAGGAAATGATCTT-3' \\
\hline M115 F & 5'-CTTCCTCCTGGGCCTCGCGGCCTATGACCGCTACG-3' \\
\hline M115 R & 5'-CGTAGCGGTCATAGGCCGCGAGGCCCAGGAGGAAG-3' \\
\hline M133A F & 5'-AGATACCCAGTCCTGGCCAACCGCAAGAAGTGT-3' \\
\hline M133A R & 5'-ACACTTCTTGCGGTTGGCCAGGACTGGGTATCT-3' \\
\hline $\mathrm{R} 135 \mathrm{~F}$ & 5'-ACCCAGTCCTGATGAACGCCAAGAAGTGTCTTTTGC-3' \\
\hline R135 R & 5'-GCAAAAGACACTTCTTGGCGTTCATCAGGACTGGGT \\
\hline C138A F & 5'-ATGAACCGCAAGAAGGCTCTTTTGCTGGCTGCT-3' \\
\hline C138A R & 5'-AGCAGCCAGCAAAAGAGCCTTCTTGCGGTTCAT-3' \\
\hline S190A F & 5'-CCTGTGCAGACACGGCCTTGTATGAAACTCTGA-3' \\
\hline S190A R & 5'-TCAGAGTTTCATACAAGGCCGTGTCTGCACAGG-3' \\
\hline T213A F & 5'-TCTCTATCATCTCCGCTTCCTACTCССTCATC-3' \\
\hline T213A R & 5'-GATGAGGGAGTAGGAAGCGGAGATGATAGAGA-3' \\
\hline T221A F & 5'-CCCTCATCTTGTTAGCCATCCACCGCATGCCCT-3' \\
\hline T221A R & 5'AGGGCATGCGGTGGATGGCTAACAAGATGAGGG-3' \\
\hline C238S F & 5'AAAGGCCTTCACCACTAGCTCCTCCCACTTGACTG-3' \\
\hline C238S R & 5'-CAGTCAAGTGGGAGGAGCTAGTGGTGAAGGCCTTT-3' \\
\hline H241R F & 5'-CACCACTTGTTCCTCCCGCTTGACTGTAGTTAGCA-3' \\
\hline H241R R & 5'-TGCTAACTACAGTCAAGCGGGAGGAACAAGTGGTG-3' \\
\hline P265A F & 5'-GTCCTTCCACACCGCCGAGCAGGACAAAGTAG-3' \\
\hline P265A R & 5'-CTACTTTGTCCTGCTCGGCGGTGTGGAAGGAC-3' \\
\hline V270A F & 5'-CGAGCAGGACAAAGCAGTGTCAGCCTTCTATA-3' \\
\hline V270A R & 5'-TATAGAAGGCTGACACTGCTTTGTCCTGCTCG-3' \\
\hline G296A F & 5'ACAAGGACGTCATAGCGGCATTTAAAAAGGT-3' \\
\hline G296A R & 5'-ACCTTTTTAAATGCCGCTATGACGTCCTTGT-3' \\
\hline
\end{tabular}

MOR244-2

\begin{tabular}{|c|c|}
\hline M104A F & 5'-TGCCTGTGTGGTCCAGGCGTTCTTCCTGCACCT-3' \\
\hline M104A R & 5'-AGGTGCAGGAAGAACGCCTGGACCACACAGGCA-3' \\
\hline M104C F & 5'-TGCCTGTGTGGTCCAGTGCTTCTTCCTGCACCT-3' \\
\hline M104C R & 5'-AGGTGCAGGAAGAAGCACTGGACCACACAGGCA -3' \\
\hline M104E F & 5'-TGCCTGTGTGGTCCAGGAGTTCTTCCTGCACCT-3' \\
\hline
\end{tabular}




\begin{tabular}{|c|c|}
\hline M104E R & 5'- AGGTGCAGGAAGAACTCCTGGACCACACAGGCA-3' \\
\hline M104H F & 5'-TGCCTGTGTGGTCCAGCACTTCTTCCTGCACCT-3' \\
\hline M104H R & 5'-AGGTGCAGGAAGAAGTGCTGGACCACACAGGCA-3' \\
\hline M104V F & 5'-TGCCTGTGTGGTCCAGGTGTTCTTCCTGCACCT-3' \\
\hline M104V R & 5'-AGGTGCAGGAAGAACACCTGGACCACACAGGCA-3' \\
\hline M108A F & 5'-AGATGTTCTTCCTGGCGCTCTTTGCCTGCAC-3' \\
\hline M108A R & 5'-GTGCAGGCAAAGAGCGCCAGGAAGAACATCT-3' \\
\hline M108M F & 5'-CCAGATGTTCTTCCTGATGCTCTTTGCCTGCACAG-3' \\
\hline M108M R & 5'-CTGTGCAGGCAAAGAGCATCAGGAAGAACATCTGG-3' \\
\hline
\end{tabular}




\section{References}

(1) Sekharan, S.; Ertem, Mehmed Z.; Zhuang, H.; Block, E.; Matsunami, H.; Zhang, R.; Wei, Jennifer N.; Pan, Y.; Batista, Victor S. Biophys. J. 2014, 107, L5-L8.

(2) Haga, K.; Kruse, A. C.; Asada, H.; Yurugi-Kobayashi, T.; Shiroishi, M.; Zhang, C.; Weis, W. I.; Okada, T.; Kobilka, B. K.; Haga, T.; Kobayashi, T. Nature 2012, 482, 547-551.

(3) Maestro version 10.2, Schrödinger, LLC, New York, NY 2015.

(4) Li, H.; Robertson, A. D.; Jensen, J. H. Proteins 2005, 61, 704-721.

(5) Madhavi Sastry, G.; Adzhigirey, M.; Day, T.; Annabhimoju, R.; Sherman, W. J. Comput. Aided Mol. Des. 2013, 27, 221-234.

(6) Zhao, Y.; Truhlar, D. G. J. Chem. Phys. 2006, 125, 194101.

(7) Zhao, Y.; Truhlar, D. G. Theor. Chem. Account 2008, 120, 215-241.

(8) Wiberg, K. B. J. Comput. Chem. 1986, 7, 379.

(9) Cornell, W. D.; Cieplak, P.; Bayly, C. I.; Gould, I. R.; Merz, K. M.; Ferguson, D. M.; Spellmeyer, D. C.; Fox, T.; Caldwell, J. W.; Kollman, P. A. J. Am. Chem. Soc. 1995, 117, 5179-5197.

(10) Vreven, T.; Morokuma, K.; Farkas, Ö.; Schlegel, H. B.; Frisch, M. J. J. Comput. Chem. 2003, 24, 760-769.

(11) Frisch, M. J.; Trucks, G. W.; Schlegel, H. B.; Scuseria, G. E.; Robb, M. A.; Cheeseman, J. R.; Scalmani, G.; Barone, V.; Mennucci, B.; Petersson, G. A.; Nakatsuji, H.; Caricato, M.; Li, X.; Hratchian, H. P.; Izmaylov, A. F.; Bloino, J.; Zheng, G.; Sonnenberg, J. L.; Hada, M.; Ehara, M.; Toyota, K.; Fukuda, R.; Hasegawa, J.; Ishida, M.; Nakajima, T.; Honda, Y.; Kitao, O.; Nakai, H.; Vreven, T.; Montgomery Jr., J. A.; Peralta, J. E.; Ogliaro, F.; Bearpark, M. J.; Heyd, J.; Brothers, E. N.; Kudin, K. N.; Staroverov, V. N.; Kobayashi, R.; Normand, J.; Raghavachari, K.; Rendell, A. P.; Burant, J. C.; Iyengar, S. S.; Tomasi, J.; Cossi, M.; Rega, N.; Millam, N. J.; Klene, M.; Knox, J. E.; Cross, J. B.; Bakken, V.; Adamo, C.; Jaramillo, J.; Gomperts, R.; Stratmann, R. E.; Yazyev, O.; Austin, A. J.; Cammi, R.; Pomelli, C.; Ochterski, J. W.; Martin, R. L.; Morokuma, K.; Zakrzewski, V. G.; Voth, G. A.; Salvador, P.; Dannenberg, J. J.; Dapprich, S.; Daniels, A. D.; Farkas, Ö.; Foresman, J. B.; Ortiz, J. V.; Cioslowski, J.; Fox, D. J.; Gaussian, Inc.: Wallingford, CT, USA, 2009.

(12) Andrae, D.; Häußermann, U.; Dolg, M.; Stoll, H.; Preuß, H. Theoret. Chim. Acta 1990, 77, 123-141.

(13) Bakowies, D.; Thiel, W. J. Phys. Chem. 1996, 100, 10580-10594.

(14) Sekharan, S.; Mooney, V. L.; Rivalta, I.; Kazmi, M. A.; Neitz, M.; Neitz, J.; Sakmar, T. P.; Yan, E. C. Y.; Batista, V. S. J. Am. Chem. Soc. 2013, 135, 19064-19067.

(15) Wang, J.; Luthey-Schulten, Z. A.; Suslick, K. S. P. Natl. Acad. Sci. U. S. A. 2003, 100, 3035-3039.

(16) Wu, Z.; Fernandez-Lima, F. A.; Russell, D. H. J. Am. Soc. Mass. Spect. 2010, 21, 522-533.

(17) Rubino, J. T.; Riggs-Gelasco, P.; Franz, K. J. J. Biol. Inorg. Chem. 2010, 15, 1033-1049.

(18) Duan, X.; Block, E.; Li, Z.; Connelly, T.; Zhang, J.; Huang, Z.; Su, X.; Pan, Y.; Wu, L.; Chi, Q.; Thomas, S.; Zhang, S.; Ma, M.; Matsunami, H.; Chen, G.-Q.; Zhuang, H. Proc. Natl. Acad. Sci. U. S. A. 2012, 109, 3492-3497.

(19) Akoka, S.; Barantin, L.; Trierweiler, M. Anal. Chem. 1999, 71, 2554-2557. 